\title{
Time-Varying Liquidity Trading, Private Information and Insider Trading
}

\author{
Qin Lei
}

Finance Department, Cox School of Business at Southern Methodist University, 6212 Bishop Blvd, Dallas, TX 75275-0333, USA

E-mail:leiq@umich.edu

\section{Xuewu Wang}

Department of Economics and Finance, Kania School of Management at the University of Scranton, 320 Madison Avenue, Scranton, PA 18510, USA

E-mail:xuewuw@umich.edu

\begin{abstract}
This paper investigates the insider trading before scheduled versus unscheduled corporate announcements to explore how corporate insiders utilise their private information in response to the time-varying liquidity trading. Using a comprehensive insider trading database, we show that: (1) the insider's propensity to trade increases in the amount of liquidity trading before both the scheduled and unscheduled announcements; (2) insiders buy (sell) more before positive (negative) announcements; and (3) insider purchases are more profitable before unscheduled announcements than before scheduled ones. They suggest that insiders time their trades around scheduled and unscheduled announcements to exploit the varying extent of liquidity trading.
\end{abstract}

Keywords: time varying, liquidity trading, insider trading

JEL classification: $G 10, G 14$

\section{Introduction}

One fundamental question in the field of market microstructure is how private information gets incorporated into asset prices through the trading process. It is now generally accepted that such private information is often revealed through orders

The authors are grateful to John Doukas (the editor) and an anonymous referee for their insights that greatly strengthened the paper. The authors also thank participants at the FMA 2010 meeting in New York and especially Bonnie Van Ness (the discussant) for their helpful comments and suggestions. 
from informed traders and through learning these orders by other market participants such as market makers and uninformed traders. From this perspective, studying the interaction between informed traders and uninformed traders (also known as liquidity traders) is especially important for a better understanding of the private information incorporation process. Approximating corporate insiders as informed traders, this paper studies insider trades around two distinct settings, i.e., scheduled versus unscheduled corporate announcements, to investigate how insiders trade differently based on their private information when there is a dispersion in the amount of liquidity trading around such announcements. ${ }^{1}$

Scheduled and unscheduled announcement events are distinguishable by the public availability of the timing information as to when an announcement will be issued. Scheduled announcements are those where such information is publicly available in advance whereas unscheduled announcements refer to cases where such information is not. Chae (2005) argues that the availability of the timing information about corporate announcements gives rise to distinct trading patterns by liquidity traders. More specifically, when timing information is available in advance, discretionary liquidity traders in the sense of Admati and Pfleiderer (1988) know that a large amount of information will be released on a known date. Since they do not know whether the information will be positive or negative, they might respond by changing the timing of their trades. For example, they might postpone their trades until after the announcements if they anticipate adverse price movements associated with the information release. In contrast, when timing information is not available prior to the actual announcements, liquidity traders have no bases to time their trades and trade just as usual. Consistent with this argument, Chae (2005) finds and we are able to confirm that abnormal trading volume increases before unscheduled announcements and decreases before scheduled announcements.

This paper takes the analysis in Chae (2005) one step further by examining insider trades before scheduled versus unscheduled announcements. We aim at investigating whether or not insiders indeed respond to the time variation in liquidity trading before different announcements. This question is critically important to the strategic trading literature. Models of strategic trading predict that informed traders will try to hide their trades among liquidity trading so as to prevent their private information from being revealed fully and instantaneously. ${ }^{2}$ To the extent that the amount of liquidity trading is time-varying around scheduled versus unscheduled announcements, the varying trading patterns imply different levels of camouflage for insider trades. Consequently, the decisions of whether and how insiders trade before announcements can be influenced by the time-varying liquidity trading before such announcements, and this paper carries out the tests to see if the data support these predictions.

Following Chae (2005), we treat quarterly earnings announcements as scheduled announcements while the announcements of mergers and acquisitions are considered as unscheduled announcements. Chae (2005) chooses these two types of announcements

\footnotetext{
${ }^{1}$ Given their unique informational advantages, corporate insiders are quite natural proxies for informed traders. The presence of ample corporate events makes this approximation even more appealing when we examine insider trades under asymmetric information.

${ }^{2}$ An incomplete list of strategic trading literature includes Kyle (1985, 1989), Admati and Pleiderer (1988), Holden and Subramanyam (1992), Foster and Viswanathan (1994, 1996), and Huddart et al. (2001).
} 
because they represent major corporate events with substantial impacts on stock prices. ${ }^{3}$ Quarterly earnings announcements are labelled as scheduled announcements because public companies routinely make such announcements with a commonly known schedule. ${ }^{4}$ In contrast, neither the timing nor the magnitude/direction of information about the announcements of mergers and acquisitions is publicly available ahead of the time.

Using a comprehensive insider trading database between 1986 and 2009, we show that the insider's propensity to trade before corporate announcements increases in the amount of liquidity trading before both scheduled and unscheduled announcements. Moreover, this effect is more pronounced before unscheduled announcements than before scheduled announcements. We also find that insiders tend to buy (sell) more before announcements that have positive (negative) announcement returns, with a much stronger association before unscheduled announcements than before scheduled ones. Consistent with the traditional finding in the insider trading literature that insider purchases are informative, we demonstrate that insider purchases are much more profitable before unscheduled announcements than before scheduled ones. Taken together, our empirical results provide direct evidence that insiders time their trades around scheduled and unscheduled announcements to take advantage of the varying extent of liquidity trading. This strategic nature of their trade timing is manifested in the insider's decision to trade, the insider's direction of trade and the profitability of their trades before such announcements. This study makes a unique contribution by providing an empirical validation for the theoretical models in the strategic trading literature and helps us better understand the interactions between informed and uninformed investors.

Beyond the strategic trading literature, our paper is also closely related to the insider trading literature that has separately investigated insider trading around earnings announcements and announcements of mergers and acquisitions. ${ }^{5}$ While these studies provide lots of insights into the informational content of insider trades around such announcement events, none of them exploits the unique feature of time-varying liquidity trading surrounding these two types of announcements to investigate how insiders might take advantage of the time variation to camouflage their trades. By utilising the dispersion in the amount of liquidity trading around such announcement events, our paper is the first one to contrast insider trading before these two types of corporate announcements simultaneously from the perspective of strategic trading. The voluminous insider trading data we use in this paper, combined with the rich sets of corporate announcements, provide an ideal setting for our research purpose.

\footnotetext{
${ }^{3}$ See Ball and Brown (1968), Jensen and Ruback (1983), Bamber (1987), Bernard and Thomas (1989), Jarrell and Poulsen (1989), Ball and Kothari (1991), Mitchell et al. (2004) and others for studies on stock prices around such events.

${ }^{4}$ Bagnoli et al. (2002) document evidence that firms usually announce earnings on the planned-and-disclosed date, which suggests that earnings announcement dates are known in advance. Chordia et al. (2001) also argue that earnings announcements are among the best candidates for scheduled announcements that involve a release of relevant pricing information.

${ }^{5}$ See Sivakumar and Waymire (1994), Ke et al. (2003), Roulstone (2006), Betzer and Theissen (2009) and others for insider trading around earnings announcements. Also refer to Keown and Pinkerton (1981), Jarrell and Poulsen (1989), Meulbroek (1992), Cornell and Sirri (1992), Eyssell and Arshadi (1993) and others for insider trading around mergers and acquisitions.
} 
Our paper contributes to the insider trading literature by shedding new light on the insiders' trade timing. A few other studies have examined insider's trade timing under different settings. For instance, Garfinkel (1997) studies how insider trades respond to changes in regulatory environment. He finds that insiders alter the timing of their trades around earnings announcements with the passage of the Insider Trading and Securities Fraud Enforcement Act (ITSFEA). More specifically, insiders have emphasised more on post-earnings-announcement trades than pre-announcement trades since the ITSFEA. Friederich et al. (2002) find that corporate insiders engage in short-term market timing as medium-sized insider trades are more informative for short-term returns than large ones. Huddart et al. (2007) investigate how insiders time their trades on jeopardy associated with their trades. They find that insiders condition their trades on foreknowledge of pricerelevant public disclosures but avoid profitable trades when the jeopardy associated with their trades is high. Lee et al. (2008) also examine how changes in regulatory environment have affected the timing and profitability of insider trading over the 1986-2004 period. Consistent with the increased regulatory scrutiny, they find that there has been a steady increase over time in the proportion of trades by insiders that occur right after quarterly earnings announcements. Wang and $\mathrm{Zu}$ (2013) develop a multiple-period competitive rational expectations model to examine how informed traders time their trading on private information in order to maximise their expected utility. Similar to these papers, we examine the insiders' trade timing before scheduled and unscheduled announcements. Distinctly different from these papers though is our focus on the implications of the amount of liquidity trading before different announcements on whether and how insiders trade. We provide direct evidence that insiders exploit the diverging patterns of liquidity trading before such announcements.

The balance of the paper is organised as follows. In Section 2 we formally develop the main hypotheses. Section 3 describes the methodology of constructing our sample. We discuss in Section 4 the main empirical results and conclude in Section 5.

\section{Hypothesis Development}

As discussed in the introduction, we classify major corporate announcements based on the availability of information about the announcement date. Quarterly earnings announcements are routinely scheduled ahead of time so the earnings announcement dates are usually known beforehand. Bagnoli et al. (2002) indeed document that many firms announce earnings on dates that are planned and disclosed well in advance. ${ }^{6}$ In contrast, announcements of mergers and acquisitions are usually unscheduled and unexpected. Uninformed investors cannot predict whether and when such an announcement will be made until it becomes publicly known.

Depending upon the availability of timing information, discretionary liquidity traders can change their trading pattern in anticipation of the scheduled announcements but cannot do so ahead of the unscheduled announcements. Large shifts in liquidity traders' trading pattern may lead to distinct fluctuations of the amount of liquidity trading around these two types of announcements. In response to the heightened possibility of trading with informed traders in the case of scheduled announcements, uninformed traders will

\footnotetext{
${ }^{6}$ They also show that any delay in scheduled earnings announcements leads to significantly negative stock price reactions and economic losses for such firms, which they refer to as 'a day late, a penny short'.
} 
participate less in the market, or, in an extreme scenario, entirely exit the stock market before such announcements are made so as to avoid losing to the informed traders. ${ }^{7}$ Consequently, the amount of liquidity trading might decrease prior to the scheduled announcements. For the reduction of liquidity trading to materialise, it is important that the uninformed investors perceive a high level of information asymmetry and rationally expect to be ripped off by informed traders during such a trading environment. This strategic response should be more pronounced for scheduled announcements than for unscheduled ones due to the lack of advance disclosure in the timing information for the unscheduled announcements. In other words, uninformed traders may be able to curtail their trades prior to scheduled announcements in reaction to the possibility of stronger trading demand from informed traders and higher adverse selection costs. On the other hand, uninformed traders cannot predict when unscheduled announcements will take place, and thus they will trade as usual. Naturally, this reasoning leads to the prediction of more liquidity trading before unscheduled announcements than before scheduled announcements.

From a game-theoretic viewpoint, informed traders would not stand still in this context. In fact, insiders can plan their trades in anticipation of the different trading patterns of liquidity traders before scheduled versus unscheduled announcements. Insiders have to decide whether or not to trade ahead of the announcements and how to trade conditional on their decision to trade. Insiders may decide to trade before the announcements if the benefits from trading outweigh the costs of trading. The trading benefits mainly stem from the informational advantages that insiders have prior to the public announcements. Insiders may also exercise caution against trading prior to the announcements because of costs related to regulatory scrutiny and litigation risks. ${ }^{8}$ Insiders will suffer substantial pecuniary and non-pecuniary losses if they are caught trading on private information prior to the public disclosure.

The varying degree of pre-announcement liquidity trading is certainly relevant to the aforementioned cost-benefit analysis for insiders and can well affect insider moves. Strategic trading models suggest that it is desirable for informed traders to hide their information-based trades among liquidity trades. To the extent that higher liquidity trading provides better camouflage for informed trades, higher amount of liquidity trading implies greater benefits of trading for insiders. All else being equal, the higher the liquidity trading before announcement events, the easier it is for insiders to camouflage their trades and thus the more likely insiders will trade prior to the announcements. In other words, the insider's propensity to trade should be positively related to the amount of liquidity trading prior to both types of announcements. Since this positive relationship naturally extends from the predictions of strategic trading models, we expect this relationship to hold for both scheduled and unscheduled announcements. This explicit prediction becomes part of our first hypothesis.

In the first hypothesis, we further conjecture that the positive relationship is stronger for unscheduled announcements than for scheduled announcements. Intuitively, higher liquidity trading before unscheduled announcements provides better cover and hence implies greater benefits for insiders who indeed trade prior to the unscheduled announcements. Therefore, there should be a higher probability for insiders to trade

\footnotetext{
${ }^{7}$ See Milgrom and Stokey (1982) and Wang (1994) for the famous no-trade theorem and its extension.

${ }^{8}$ Bris (2005) studies the effectiveness of the insider trading laws around the world.
} 
in this context. In contrast, insiders are less able to hide their trades before scheduled announcements because of the lower amount of liquidity trading. Ceteris paribus, insiders will be more likely to trade before unscheduled announcements. We formalise the hypothesis as follows.

Hypothesis 1: There is a positive relationship between the amount of liquidity trading and the insider's propensity to trade before announcements. Ceteris paribus, this positive relationship should be stronger for unscheduled announcements than for scheduled ones.

We then analyse how insiders may trade conditional on their decision to trade prior to the announcements. Pre-announcement insider trades may be driven by information reasons or non-information reasons. To the extent that pre-announcement insider trades are driven by informational considerations, the insiders' trading direction (their decision to buy versus sell) should be in line with the direction of information shock. More specifically, insiders will buy (sell) more before announcements with positive (negative) valuation shock. To the extent that pre-announcement insider trades are motivated by non-information reasons, the insiders' trading direction may not be related to the informational content of the announcements. Given that insider trading leading up to corporate announcements can be quite sensitive and eye-catching, it is reasonable to argue that a large portion of insider trading immediately before announcements is driven by informational motives. Otherwise, insiders could have chosen to postpone their liquidity trades until after the public announcements to avoid regulatory scrutiny and mitigate litigation risks. ${ }^{9}$ In other words, we conjecture that there exists a positive relationship between insiders' signed volume and the informational content of the announcements.

As we have done in formulating the first hypothesis, we also posit that the effect associated with the unscheduled announcements should be stronger than that with the scheduled announcements. To the extent that pre-unscheduled-announcement liquidity trading provides better camouflage for insider trades, it is more likely that insider trades before unscheduled announcements are motivated by private information than insider trades before scheduled announcements. In other words, the positive relationship between insiders' signed volume and the informational content of announcements should be stronger before unscheduled announcements than before scheduled ones. Formally, the predictions regarding how insiders trade are stated as follows.

Hypothesis 2: There is a positive relationship between the insiders' signed volume and the informational content of corporate announcements, and this positive association should be stronger before unscheduled announcements than for scheduled ones.

As a direct corollary of the second hypothesis, our third hypothesis concerns the profitability analysis of insider trades before scheduled and unscheduled announcements. More specifically, given that insider trades before unscheduled announcements are more likely to be information-driven than those before scheduled announcements, preunscheduled-announcement insider trades should be more profitable than those before scheduled ones.

\footnotetext{
${ }^{9}$ The literature has documented evidence that insiders postpone their liquidity trades with the passage of insider trading regulation. See Garfinkel (1997), among others, for details.
} 
Hypothesis 3: Ceteris paribus, the insider trades before unscheduled announcements should be more profitable than those before scheduled announcements.

Before empirically testing these hypotheses, we briefly discuss the data sources and our strategy of constructing the sample.

\section{Sample Construction}

This study utilises a number of data sources. Stock characteristics such as daily returns, daily trading volume and book-to-market ratios are based on the Center for Research in Securities Prices (CRSP) and Compustat databases. In the rest of this section we focus on the details of constructing the final sample of corporate announcements and insider trades.

\section{$3.1 \mathrm{I} / \mathrm{B} / \mathrm{E} / \mathrm{S}$ and $S D C$ data}

Our data on corporate announcements are mainly from two sources. The I/B/E/S actuals file provides earnings announcements data, including firm name, firm identifier and earnings announcement dates. The SDC platinum database from Thomson Financial Securities Data makes available information on the target and acquirer in announcements of mergers and acquisitions involving stocks listed on NYSE, AMEX and NASDAQ.

We apply a number of filters to refine the corporate announcements for our research purpose. Since we use earnings announcements as proxies for scheduled announcements, we impose the regularity of quarterly earnings announcements. In other words, any two consecutive earnings announcements have to be 90 days apart from each other. This requirement filters out earnings announcements that are made on irregular or unscheduled dates. Moreover, the two types of announcements concerning earnings as well as mergers and acquisitions may arrive for the same firm on closely adjacent dates. In such cases, it would be difficult to unambiguously classify insiders' trades as pre-earnings-announcement or pre-merger-announcement trades. To mitigate the confounding effects of these two types of announcements that took place in a clustered fashion, we pool all announcements together and require that any two successive announcements from the same firm must be at least 30 days apart from each other.

Having satisfied the above filters and survived the matching process among different databases through common firm identifiers (CUSIP numbers), a total of 235,788 $(53,569)$ earnings (mergers and acquisitions) announcements emerge from the sample period between 1986 and 2009.

For each announcement event in our sample, we define $[t-30, t-2]$ as the preannouncement period and $[t-1, t+1]$ as the announcement period, where $t$ denotes the announcement date. To capture the firm- and event-specific characteristics, we construct a number of control variables while following the standard practice in the literature when possible. There are six such variables in total. (1) We cumulate the raw daily abnormal trading volume $\left(\right.$ Cumabvol $_{\text {raw }}$ ) over $[t-30, t-2]$. Similar to Chae (2005), trading volume is defined as the natural log of shares traded scaled by shares outstanding. Abnormal trading volume is calculated by subtracting the average trading volume over the benchmark period $[t-60, t-31]$ from the daily trading volume inside $[t-30, t-2]$. (2) The pre-announcement stock price runup (Runup) is defined as the abnormal stock returns cumulated over $[t-30, t-2]$. To calculate abnormal 
returns, a market model is first estimated over $[t-210, t-31]$. The estimates from the market model are then used to calculate daily abnormal returns. This variable helps us to proxy for information leakage in the days immediately before corporate announcements. $^{10}$ (3) We also compute the market capitalisation for each firm (Size) as the natural log of shares outstanding multiplied by the closing price. Size is measured as of the announcement month end. (4) The announcement return (AnnRet) is defined as the abnormal returns cumulated over $[t-1, t+1]$, to capture the informational content of corporate announcements. ${ }^{11}$ (5) Past stock returns (PastRet) are defined as the buyand-hold stock return cumulated over $[t-210, t-31] .{ }^{12}$ (6) Finally, we calculate the book-to-market ratio $(B M)$ for each firm as of the announcement month end. Table 1 provides the summary statistics for these control variables. Panels A and B separately report the summary statistics for the scheduled and unscheduled announcements.

\subsection{Insider trading data}

Insider trading data are obtained from First Call/Thomson Financial Insider Research Services Historical Files. The insider trading records are the transactions of persons subject to the disclosure requirements of Section 16(a) of the Securities and Exchange Act of 1934 reported on Form 4 and 5. ${ }^{13}$ Among the information required on Form 4 are: name and address of the reporting person, issuer name and ticker or trading symbol, relationship of the reporting person to the issuer (officers, directors or other positions held by the reporting persons in issuers), indicator of whether it is a purchase or sale, the date, price and trade size of the transaction. Since it has been documented that this database contains a number of data errors, we impose a number of filters to cleanse this database. ${ }^{14}$ We require that trading records have a matching CUSIP with data available from CRSP and only open market transactions in equity securities are considered in this sample. Moreover, the transaction price for any reported trades must stay within the daily price range as recorded in CRSP for the corresponding trading day. We further impose a minimum transaction price of one dollar and a minimum share volume of one

${ }^{10}$ Jarrell and Poulsen (1989) argue that information leakage before tender offer announcements can be measured by the stock price runup in the pre-announcement period.

${ }^{11}$ We employ announcement return as a proxy for the informational content of corporate announcements for two reasons. First, Brandt et al. (2008) argue that earnings announcement return is a better measure of the news in the announcement than earnings surprise in that it also contains unexpected information about company sales, margins, investment and other less tangible information communicated via the earnings announcement. Second, the announcement returns can be calculated for both the earnings announcements and the announcements of mergers and acquisitions. This ensures that the informational content of scheduled and unscheduled announcements is to some extent comparable.

${ }^{12}$ This control variable is included since Rozeff and Zaman (1998), among others, argue that past stock returns matter for insider trading.

${ }^{13}$ According the Securities and Exchange Act of 1934, the term 'corporate insider' refers to corporate officers, directors and large shareholders who own more than $10 \%$ of the firm's stock. If insiders buy or sell their firm's stock, they are mandated to file with the Securities and Exchanges Commission (SEC) within the first 10 days of the next month after their transactions. Starting from 29 August 2002, insiders are required to report their trades within two business days.

${ }^{14}$ See Appendix A in Jeng et al. (2003) for more details. 
Table 1

Summary statistics of core variables

This table presents the summary statistics of the core variables underlying corporate announcements in the sample. We define trading volume as the natural log of shares traded scaled by shares outstanding. Daily abnormal trading volume is calculated by subtracting the average trading volume over $[t-60, t-31]$ from the daily trading volume over $[t-30, t-2]$. Daily abnormal trading volume is then averaged across all announcements and cumulated over $[t-30, t-2]$ to obtain the raw cumulative abnormal trading volume (Cumabvol $l_{\text {raw }}$ ). The pre-announcement stock price runup (Runup) is defined as the abnormal stock returns cumulated over $[t-30, t-2]$. The market capitalisation for each firm (Size) is defined as the natural log of shares outstanding multiplied by the closing price at the announcement month end. The announcement return (AnnRet) is the abnormal stock returns cumulated over $[t-1, t+1]$. Past stock returns (PastRet) are defined as the buy-and-hold stock returns cumulated over $[t-210, t-31]$. The book-to-market ratio $(B M)$ is measured as of the announcement month end. Panel A provides the summary statistics for the scheduled announcements and Panel B for the unscheduled announcements.

Panel A: Scheduled announcements

\begin{tabular}{lcrrrrrrr}
\hline & $\mathrm{N}$ & \multicolumn{1}{c}{ Min } & Mean & P25 & Median & P75 & Max & Std \\
\hline Cumabvol $_{\text {raw }}$ & 235788 & -71.494 & -0.174 & -3.797 & -0.294 & 3.222 & 81.408 & 6.409 \\
Runup & 235788 & -0.947 & -0.008 & -0.081 & -0.014 & 0.051 & 6.329 & 0.166 \\
Size & 235788 & 4.725 & 12.410 & 11.012 & 12.292 & 13.692 & 20.056 & 1.953 \\
AnnRet & 235788 & -0.860 & -0.001 & -0.035 & -0.002 & 0.032 & 2.957 & 0.089 \\
PastRet & 235788 & -0.986 & 0.071 & -0.154 & 0.028 & 0.214 & 40.667 & 0.477 \\
BM & 235788 & -1099.754 & 1.845 & 0.339 & 0.599 & 0.955 & 7892.556 & 32.252 \\
\hline
\end{tabular}

Panel B: Unscheduled announcements

\begin{tabular}{lcrrrrrrr}
\hline & $\mathrm{N}$ & \multicolumn{1}{c}{ Min } & Mean & P25 & Median & P75 & Max & Std \\
\hline Cumabvol $_{\text {raw }}$ & 53659 & -52.817 & 0.182 & -3.690 & -0.036 & 3.679 & 86.305 & 6.829 \\
Runup & 53659 & -0.989 & -0.005 & -0.080 & -0.012 & 0.055 & 9.288 & 0.184 \\
Size & 53659 & 5.496 & 12.469 & 10.904 & 12.349 & 13.918 & 20.150 & 2.178 \\
AnnRet & 53659 & -0.801 & 0.024 & -0.018 & 0.006 & 0.042 & 7.367 & 0.125 \\
PastRet & 53659 & -0.966 & 0.095 & -0.130 & 0.041 & 0.228 & 30.769 & 0.517 \\
BM & 53659 & -319.842 & 1.925 & 0.320 & 0.554 & 0.865 & 6954.304 & 52.765 \\
\hline
\end{tabular}

hundred shares. Following Jeng et al. (2003), we also purge duplicate transactions (i.e., those with identical entries in all categories) from the final sample.

To measure insider trading activities before announcements, we define the period of 30 days before the announcement date as the pre-announcement period. Our choice of a 30-day window results from the trade-off between the data availability and the measurement accuracy. Scheduled earnings announcements are successive in nature and usually take place 90 days apart. Imposing too short an event window will drastically reduce the sample size of qualified insider trades whereas too long an event window can confound information effects from neighbouring announcement events. The postannouncement period of insider trades are similarly defined over a 30-day window. Table 2 presents the summary statistics of insider trades around our sample of corporate announcements. Panels A, B and C report the number of trades, the share volume and the dollar volume separately for the scheduled and unscheduled announcements. Panels $\mathrm{D}, \mathrm{E}$ and $\mathrm{F}$ present the number of announcements, the number of firms with insiders' 
Table 2

Insider trades around corporate announcements

This table presents the summary statistics on aggregate insider trading data around scheduled and unscheduled announcements. Insider trades are classified as pre (post) trades if the transaction date falls within thirty days before (after) scheduled/unscheduled announcements. The sample period is from 1986 to 2009. Minimum transaction price is set to be one dollar. Panels A, B and C report the number of trades, number of shares traded and dollar value of shares traded respectively for both scheduled and unscheduled announcements. Panels D, E and F present the number of announcements in which insiders trade, number of firms in which insiders trade and number of insiders who have traded respectively.

\begin{tabular}{|c|c|c|c|c|}
\hline & \multicolumn{2}{|c|}{ Scheduled } & \multicolumn{2}{|c|}{ Unscheduled } \\
\hline & Pre & Post & Pre & Post \\
\hline \multicolumn{5}{|l|}{ Panel A: Number of trades } \\
\hline Purchases & 40456 & 137180 & 12779 & 16532 \\
\hline Sales & 190414 & 675730 & 60310 & 75222 \\
\hline Total trades & 230870 & 812910 & 73089 & 91754 \\
\hline \multicolumn{5}{|l|}{ Panel B: Number of shares traded } \\
\hline Shares bought (million) & 484.15 & 1334.61 & 250.10 & 252.95 \\
\hline Shares sold (million) & 1403.65 & 5942.97 & 787.50 & 1158.25 \\
\hline Total shares traded (million) & 1887.80 & 7277.58 & 1037.60 & 1411.19 \\
\hline \multicolumn{5}{|l|}{ Panel C: Dollar value of shares traded } \\
\hline Shares bought (\$billion) & 6.43 & 17.01 & 4.65 & 4.18 \\
\hline Shares sold (\$billion) & 33.06 & 196.03 & 34.16 & 47.14 \\
\hline Shares traded (\$billion) & 39.50 & 213.04 & 38.82 & 51.33 \\
\hline \multicolumn{5}{|l|}{ Panel D: Number of announcements } \\
\hline Announcements with insider purchases & 7894 & 27314 & 3108 & 3801 \\
\hline Announcements with insider sales & 14389 & 45910 & 5448 & 6194 \\
\hline Announcements with insider trades & 21280 & 65806 & 7930 & 9198 \\
\hline \multicolumn{5}{|l|}{ Panel E: Number of insider trading firms } \\
\hline Firms with insider purchases & 3699 & 7284 & 2156 & 2513 \\
\hline Firms with insider sales & 4778 & 7294 & 2797 & 3127 \\
\hline Firms with insider trades & 6222 & 8880 & 3894 & 4345 \\
\hline \multicolumn{5}{|l|}{ Panel F: Number of insiders } \\
\hline Insiders with purchases & 7921 & 27327 & 4241 & 5300 \\
\hline Insiders with sales & 14321 & 48810 & 8746 & 10430 \\
\hline Insiders with trades & 20988 & 66873 & 12502 & 15046 \\
\hline
\end{tabular}

trades and the number of insiders who have traded in the pre- and post-announcement periods. For each variable, we report the summary statistics for the total trades as well as statistics separating insider purchases from insider sales. When tallying the number of announcements in connection with insider trades, Panel D reports a lower number of announcements than the sum of announcements with insider purchases and 
announcements with insider sales. This is clearly due to the fact that insiders can choose to both buy and sell stocks prior to any given announcement. ${ }^{15}$ The same logic applies to Panels $\mathrm{E}$ and $\mathrm{F}$ as well.

It is apparent from Table 2 that insiders submit a vast amount of trades immediately before corporate announcements. While conventional wisdom suggests that insiders might avoid trading immediately before corporate announcements due to regulatory scrutiny and litigation concerns, $20,988(12,502)$ corporate insiders from $6,222(3,894)$ firms jointly make $230,870(73,089)$ trades totalling 39.50 (38.82) billion dollars immediately before scheduled (unscheduled) announcements during our sample period between 1986 and 2009. An average insider makes 5.11 (3.01) purchases during the period of 30 days before scheduled (unscheduled) announcements. In comparison, an average insider makes 13.30 (6.90) sales before scheduled (unscheduled) announcements. Insiders seem to refrain themselves more from making purchases than making sales before announcements, which is consistent with the finding in the literature that insider purchases are more likely to be information-driven than insider sales. On average, insiders as a group make 10.85 (9.22) trades immediately before each scheduled (unscheduled) announcement. While our sample contains a total of 235,788 $(53,659)$ scheduled (unscheduled) announcements, insiders only trade before 21,280 $(7,930)$ scheduled (unscheduled) announcements. The fact that insiders choose not to trade before the vast majority of announcements is consistent with the deterrent effect of litigation concerns and self-instituted corporate policies restricting insider trades during such periods.

\section{Empirical Results}

\subsection{Liquidity trading}

Before we proceed to discuss the main empirical results, it is useful to document that there is indeed a dispersion in the amount of liquidity trading before scheduled versus unscheduled announcements. This is critical to our analysis because our hypotheses about insider trading and information asymmetry stem from liquidity trading patterns associated with such events.

4.1.1 Raw cumulative abnormal trading volume. We start by replicating the trading volume patterns before scheduled and unscheduled announcements as documented in Chae (2005) using our sample. We follow the procedure in Chae (2005) and make minor changes to meet our research needs. More specifically, for each announcement event, we calculate the cumulative abnormal trading volume over $[t-30, t-2]$, where $t$ is the announcement date. ${ }^{16}$ Trading volume is defined as the natural log of shares traded scaled by shares outstanding. Abnormal daily trading volume is calculated by subtracting the mean trading volume over the benchmark period $[t-60, t-31]$ from the daily

\footnotetext{
${ }^{15}$ In other words, there is an intersection between the set of announcements with insider purchases and the set of announcements with insider sales. The union of these two sets leads to a total number of announcements fewer than the simple sum of the two.

${ }^{16}$ Different from Chae (2005), we choose the 30-day period before and after each announcement during which to measure insider trading. Choosing a very short event window would drastically reduce the sample size.
} 

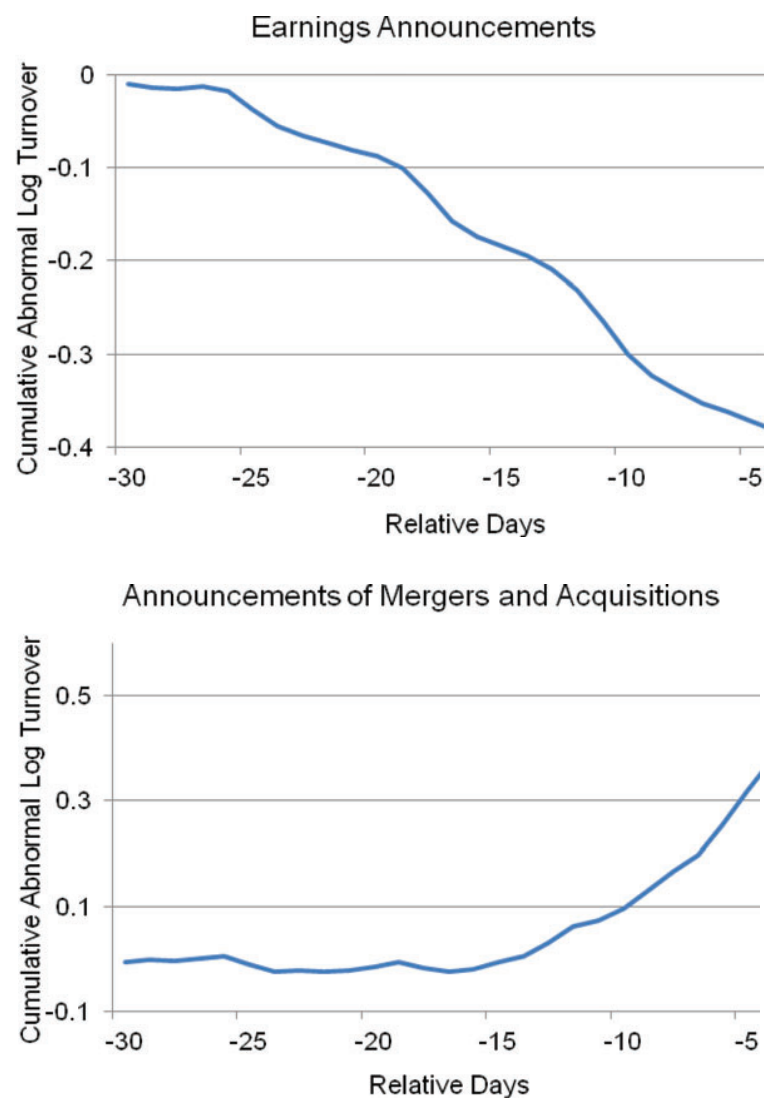

Fig. 1. Cumulative abnormal trading volume

This figure plots the raw cumulative abnormal trading volume within $[t-30, t-2]$ around scheduled and unscheduled announcement events, where $t$ is the announcement date. Trading volume is defined as the natural log of shares traded scaled by shares outstanding. Daily abnormal trading volume is calculated by subtracting the average daily trading volume over $[t-60, t-31]$ from the daily trading volume over $[t-30, t-2]$. The top graph plots the series for earnings announcements and the bottom graph for announcements of mergers and acquisitions. In both graphs, the horizontal axis is the days relative to announcement dates and the vertical axis is the cumulative abnormal trading volume.

trading volume in the pre-announcement period $[t-30, t-2] \cdot{ }^{17}$ Daily abnormal trading volume is then averaged across all announcements of a certain type and cumulated over $[t-30, t-2]$.

Figure 1 plots the cumulative abnormal trading volume separately for the scheduled and unscheduled announcements. The graphical presentation makes it clear that our sample exhibits a trading volume pattern closely resembling that in Chae (2005). Specifically, the raw abnormal trading volume goes down before scheduled

\footnotetext{
${ }^{17}$ We choose the 30-day window between two consecutive earnings announcements as the benchmark window. This seems to be a natural choice given that we focus on regular quarterly earnings announcements that are about 90 days apart from each other. To make it comparable, we employ the same benchmark and event window for unscheduled announcements.
} 
announcements and goes up before unscheduled ones. The diverging patterns of trading volume are not very sensitive to alternative specifications of the benchmark and event window. In untabulated results we also notice that both scheduled and unscheduled announcements witness increased trading volume after the announcements are made. To the extent that discretionary liquidity traders' liquidity trading demands have to be satisfied, a hike in the trading volume after earnings announcements is consistent with the idea that liquidity traders are fulfilling their trading needs.

Since the liquidity traders are increasingly likely to refrain from trading as it approaches the dates of scheduled announcements, corporate insiders are expected to make the strategic response and make fewer trades as it gets closer to the scheduled announcements. So it is important to examine the time series pattern of insider trades prior to the two types of announcements. ${ }^{18}$

Table 3 reports the insider trading activities during the 30-day period prior to each announcement date, sampled with five-day intervals. Interestingly, the empirical pattern appears closely related to the type of announcements as one would expect. The insiders indeed trade less in the five days immediately preceding the scheduled announcements than in the more distant past, even though the general decline in insider trading activities is not strictly monotonic. This time-series pattern is clear when we measure the insider trades by the number of trades (both purchases and sales), the share volume and the dollar volume. In contrast, the insiders do not exhibit the same time series patterns in the days leading up to the unscheduled announcements. Presumably, the predictable nature of the drop in liquidity trading right before the scheduled announcements contributes to the difference in the time series patterns.

One striking feature of the time-series patterns of insider trades is the sudden and dramatic spike in insider share volume and dollar volume of purchases in the five days prior to the unscheduled announcements, according to Panel B of Table 3 . This unique pattern appears confined to insider purchases and only prior to the unscheduled announcements. To better understand the source of this hike in insider purchases, we further separate insider trades by the subsequent announcement returns and present their time-series patterns in Panels $\mathrm{C}$ and D prior to the scheduled and the unscheduled announcements, respectively.

Garfinkel (1997), among others, classify insider purchases (sales) prior to announcements with positive (negative) announcement returns as informative. Notice that this separation of insider trades in Panel $\mathrm{C}$ based on the informativeness of trades does not alter the general decline of insider volume prior to scheduled announcements. Insider trades prior to unscheduled announcements in Panel D present a stark contrast, however. It turns out that the aforementioned spike in insider purchases prior to unscheduled announcements is almost entirely driven by insiders who submitted buy orders prior to positive announcements.

Specifically, there is a nearly fivefold increase in informative insider purchases (i.e., buying prior to positive announcements) in the five days prior to unscheduled announcements as opposed to in the $[t-30, t-26]$ period when we measure insider purchases by share volume. When dollar volume is used instead, there is a more than sevenfold increase. Interestingly, the informative insider purchases are fairly steady in the 25 days leading up to the dramatic spike. On the other hand, the uninformative insider

\footnotetext{
${ }^{18}$ We thank the editor and the anonymous referee for this insight.
} 
Table 3

Time series patterns of pre-announcement insider trading

This table presents the time series pattern of insider trading before scheduled and unscheduled announcements. The pre-announcement thirty-day window $[t-30, t-1]$ is partitioned into six fiveday intervals, where $t$ is the announcement date. Summary statistics on the number of trades, dollar volume and share volume are provided for both insider purchases and sales. Panels A and C provide the summary statistics for the scheduled announcements while Panels B and D do so for the unscheduled announcements. Insider trades are further classified as informative among purchases (or sales) prior to announcements with positive (or negative) announcement returns and uninformed otherwise.

Panel A: Scheduled announcements

\begin{tabular}{|c|c|c|c|c|c|c|}
\hline & $\begin{array}{l}{[t-30} \\
t-26]\end{array}$ & $\begin{array}{l}{[t-25} \\
t-21]\end{array}$ & $\begin{array}{l}{[t-20} \\
t-16]\end{array}$ & $\begin{array}{l}{[t-15} \\
t-11]\end{array}$ & $\begin{array}{c}{[t-10} \\
t-6]\end{array}$ & $\begin{array}{l}{[t-5} \\
t-1]\end{array}$ \\
\hline Number of purchases & 8467 & 6689 & 6128 & 7740 & 6518 & 4880 \\
\hline Number of sales & 41356 & 39666 & 25828 & 30226 & 30728 & 22610 \\
\hline Total number of trades & 49823 & 46355 & 31956 & 38000 & 37246 & 27490 \\
\hline Shares bought (million) & 107.06 & 88.08 & 67.30 & 79.58 & 94.74 & 47.38 \\
\hline Shares sold (million) & 312.08 & 270.79 & 280.92 & 223.81 & 181.20 & 138.84 \\
\hline Total shares traded (million) & 419.14 & 358.88 & 348.23 & 303.39 & 275.94 & 182.22 \\
\hline Shares bought (\$billion) & 1.52 & 1.15 & 0.94 & 1.17 & 1.08 & 0.57 \\
\hline Shares sold (\$billion) & 8.35 & 6.24 & 4.65 & 5.74 & 4.77 & 3.32 \\
\hline Shares traded (\$billion) & 9.88 & 7.39 & 5.59 & 6.91 & 5.85 & 3.88 \\
\hline \multicolumn{7}{|c|}{ Panel B: Unscheduled announcements } \\
\hline & $\begin{array}{c}{[t-30} \\
t-26]\end{array}$ & $\begin{array}{c}{[t-25} \\
t-21]\end{array}$ & $\begin{array}{c}{[t-20} \\
t-16]\end{array}$ & $\begin{array}{c}{[t-15} \\
t-11]\end{array}$ & $\begin{array}{c}{[t-10} \\
t-6]\end{array}$ & $\begin{array}{c}{[t-5} \\
t-1]\end{array}$ \\
\hline Number of purchases & 2555 & 2210 & 1748 & 2181 & 2226 & 1859 \\
\hline Number of sales & 13600 & 10714 & 8563 & 10921 & 9931 & 6581 \\
\hline Total number of trades & 16155 & 12924 & 10311 & 13102 & 12157 & 8440 \\
\hline Shares bought (million) & 26.37 & 19.62 & 17.56 & 47.04 & 28.60 & 110.89 \\
\hline Shares sold (million) & 196.34 & 129.33 & 117.53 & 130.85 & 118.50 & 94.95 \\
\hline Total shares traded (million) & 222.71 & 148.96 & 135.10 & 177.89 & 147.10 & 205.84 \\
\hline Shares bought (\$billion) & 0.48 & 0.35 & 0.27 & 0.67 & 0.42 & 2.47 \\
\hline Shares sold (\$billion) & 7.87 & 6.46 & 5.38 & 6.42 & 4.86 & 3.17 \\
\hline Shares traded (\$billion) & 8.36 & 6.81 & 5.64 & 7.09 & 5.28 & 5.64 \\
\hline \multicolumn{7}{|c|}{ Panel C: Unscheduled announcements } \\
\hline & $\begin{array}{c}{[t-30} \\
t-26]\end{array}$ & $\begin{array}{c}{[t-25} \\
t-21]\end{array}$ & $\begin{array}{c}{[t-20} \\
t-16]\end{array}$ & $\begin{array}{l}{[t-15} \\
t-11]\end{array}$ & $\begin{array}{c}{[t-10} \\
t-6]\end{array}$ & $\begin{array}{l}{[t-5} \\
t-1]\end{array}$ \\
\hline $\begin{array}{l}\text { Informative purchases } \\
\text { (trades) }\end{array}$ & 4319 & 3461 & 2915 & 4106 & 2843 & 2378 \\
\hline $\begin{array}{l}\text { Uninformative purchases } \\
\text { (trades) }\end{array}$ & 4148 & 3228 & 3213 & 3668 & 3675 & 2502 \\
\hline Informative sales (trades) & 21624 & 21206 & 13287 & 16589 & 17499 & 12872 \\
\hline Uninformative sales (trades) & 19732 & 18460 & 12541 & 13637 & 13229 & 9738 \\
\hline $\begin{array}{l}\text { Informative purchases } \\
\quad \text { (million shares) }\end{array}$ & 50.98 & 33.68 & 30.53 & 36.53 & 35.02 & 27.95 \\
\hline $\begin{array}{l}\text { Uninformative purchases } \\
\text { (million shares) }\end{array}$ & 56.08 & 54.40 & 36.78 & 43.05 & 59.72 & 19.43 \\
\hline
\end{tabular}


Table 3

Continued.

Panel C: Unscheduled announcements

\begin{tabular}{|c|c|c|c|c|c|c|}
\hline & $\begin{array}{c}{[t-30} \\
t-26]\end{array}$ & $\begin{array}{c}{[t-25} \\
t-21]\end{array}$ & $\begin{array}{c}{[t-20} \\
t-16]\end{array}$ & $\begin{array}{c}{[t-15} \\
t-11]\end{array}$ & $\begin{array}{c}{[t-10} \\
t-6]\end{array}$ & $\begin{array}{l}{[t-5,} \\
t-1]\end{array}$ \\
\hline $\begin{array}{l}\text { Informative sales (million } \\
\text { shares) }\end{array}$ & 177.95 & 132.67 & 179.89 & 128.53 & 108.95 & 67.46 \\
\hline $\begin{array}{l}\text { Uninformative sales (million } \\
\text { shares) }\end{array}$ & 134.14 & 138.12 & 101.03 & 95.28 & 72.25 & 67.38 \\
\hline $\begin{array}{l}\text { Informative purchases } \\
\text { (\$billion) }\end{array}$ & 0.80 & 0.44 & 0.49 & 0.51 & 0.49 & 0.33 \\
\hline $\begin{array}{l}\text { Uninformative purchases } \\
\text { (\$billion) }\end{array}$ & 0.73 & 0.71 & 0.45 & 0.66 & 0.59 & 0.24 \\
\hline Informative sales (\$billion) & 3.89 & 2.49 & 2.14 & 2.75 & 2.76 & 1.69 \\
\hline Uninformative sales (\$billion) & 4.46 & 3.75 & 2.51 & 2.99 & 2.00 & 1.62 \\
\hline
\end{tabular}

Panel D: Unscheduled announcements

\begin{tabular}{|c|c|c|c|c|c|c|}
\hline & $\begin{array}{l}{[t-30} \\
t-26]\end{array}$ & $\begin{array}{l}{[t-25} \\
t-21]\end{array}$ & $\begin{array}{l}{[t-20} \\
t-16]\end{array}$ & $\begin{array}{r}{[t-15,} \\
t-11]\end{array}$ & $\begin{array}{c}{[t-10} \\
t-6]\end{array}$ & $\begin{array}{l}{[t-5,} \\
t-1]\end{array}$ \\
\hline Informative purchases (trades) & 1547 & 1419 & 1229 & 1401 & 1336 & 1093 \\
\hline $\begin{array}{l}\text { Uninformative purchases } \\
\text { (trades) }\end{array}$ & 1008 & 791 & 519 & 780 & 890 & 766 \\
\hline Informative sales (trades) & 6966 & 5584 & 4332 & 4785 & 4323 & 3176 \\
\hline Uninformative sales (trades) & 6634 & 5130 & 4231 & 6136 & 5608 & 3405 \\
\hline $\begin{array}{l}\text { Informative purchases } \\
\text { (million shares) }\end{array}$ & 16.35 & 13.05 & 13.23 & 13.18 & 17.79 & 96.23 \\
\hline $\begin{array}{l}\text { Uninformative purchases } \\
\text { (million shares) }\end{array}$ & 10.02 & 6.58 & 4.33 & 33.87 & 10.81 & 14.66 \\
\hline $\begin{array}{l}\text { Informative sales (million } \\
\text { shares) }\end{array}$ & 103.33 & 71.01 & 61.35 & 65.08 & 62.02 & 53.54 \\
\hline $\begin{array}{l}\text { Uninformative sales (million } \\
\text { shares) }\end{array}$ & 93.01 & 58.32 & 56.19 & 65.77 & 56.48 & 41.41 \\
\hline $\begin{array}{l}\text { Informative purchases } \\
\text { (\$billion) }\end{array}$ & 0.28 & 0.23 & 0.19 & 0.23 & 0.27 & 2.31 \\
\hline $\begin{array}{l}\text { Uninformative purchases } \\
\text { (\$billion) }\end{array}$ & 0.20 & 0.11 & 0.08 & 0.44 & 0.15 & 0.16 \\
\hline Informative sales (\$billion) & 4.88 & 3.82 & 2.77 & 3.97 & 3.02 & 1.90 \\
\hline Uninformative sales (\$billion) & 3.00 & 2.64 & 2.61 & 2.45 & 1.84 & 1.27 \\
\hline
\end{tabular}

purchases (i.e., buying prior to negative announcements) have a much weaker pattern. ${ }^{19}$ Moreover, the uninformative insider purchases account for a fairly small fraction of insider volume in the five days prior to unscheduled announcements, $13.22 \%$ of share volume and $6.48 \%$ of dollar volume, while the informative insider purchases account for the lion's share.

\footnotetext{
${ }^{19}$ Comparing the uninformative insider purchases in the five days prior to unscheduled announcements to those in the $[t-30, t-26]$ period, there is a $46 \%$ hike in share volume and a $20 \%$ drop in dollar volume.
} 
These univariate results shed new light on how the type of corporate announcements and the informational content therein affect the timing decision of insider trades. The existence of a large fraction of insider purchases in the five days prior to unscheduled positive announcements, as documented in Table 3, serves as a prelude to our finding later that insiders buy (sell) more before positive (negative) announcements after controlling for a number of factors in a regression framework.

4.1.2 Orthogonalisation of cumulative abnormal trading volume. The earlier graph simply demonstrates that abnormal trading volume goes down (up) before scheduled (unscheduled) announcements. We do not know with certainty that this pattern of abnormal trading volume indeed represents the time series pattern of liquidity trading. While the actions of discretionary liquidity traders are entirely consistent with the volume pattern because of their trade timing around scheduled announcements, changes in informed trading could contribute to the observed pattern as well. Therefore, in order to adequately capture the true pattern of liquidity trading, it is important to tease out any abnormal trading volume driven by information reasons. This is not an easy task, however, given the lack of disclosure of informed trades.

In this paper we aim at decomposing the pre-announcement abnormal trading volume into two parts. One part is related to the information leakage and informational content of the announcements while the other part is unrelated to the informational aspect of the announcements, which we will refer to as 'liquidity trading'. To achieve this separation, we use a simple procedure to orthogonalise the raw abnormal trading volume. For each firm in the sample, we pool together the announcements and then regress the raw cumulative abnormal trading volume on stock price runup and announcement return corresponding to each announcement. ${ }^{20}$ The firm-level regression has the design of:

$$
\text { Cumabvol }_{\text {raw }}=\beta_{0}+\beta_{1} \cdot \text { Runup }+\beta_{2} \cdot \text { AnnRet }+\epsilon,
$$

where Cumabvol raw $_{\text {is }}$ is the raw cumulative abnormal trading volume and Runup and AnnRet are the absolute values of pre-announcement stock price runup and announcement return. The two explanatory variables are intended to capture information leakage and informational content of announcements, respectively. We use absolute values of the information proxies since both positive and negative information shocks can affect pre-announcement trading. ${ }^{21}$

Once the firm-level regressions are estimated, we obtain the residuals that are essentially the information-adjusted cumulative abnormal trading volume (Cumabvol). The rationale is that if the pre-announcement abnormal trading volume is driven by information-based trading, then trading volume should be related to information leakage and informational content of the announcements. By carving out the trading volume that is associated with information proxies of corporate announcements, we hope to obtain a cleaner measure of pre-announcement liquidity trading than the raw cumulative abnormal trading volume. In the rest of the study we use the information-adjusted cumulative abnormal trading volume as a proxy for liquidity trading.

${ }^{20}$ We require a minimum of ten announcements for each firm when running the regression. As a result, the number of scheduled (unscheduled) announcements included in the orthogonalisation procedure drops from $235,788(53,659)$ to $219,058(46,117)$.

${ }^{21}$ We appreciate this suggestion from the anonymous referee. 
It is clear that the simple orthogonalisation procedure above is not perfect. Most likely there are true information variables that are not observable to the econometrician and thus their exclusion from the regression design leads to the omitted variable bias. To the extent that the information-adjusted cumulative abnormal trading volume acts as a noisy proxy to the true amount of liquidity trading, it may introduce potentially biased inference on the estimated effects of liquidity trading on the strategic behaviour of informed traders. This empirical issue is rather difficult to tackle directly, in the absence of a full model for the determinants of raw cumulative abnormal trading volume. Nevertheless, we implement two indirect tests to mitigate the potential concern.

First, we study a specially designed subsample to address the concern that our proxy for liquidity trading may still be influenced by information leakage. ${ }^{22}$ Specifically, we focus on the subsample of announcements with opposite signs between the preannouncement-period price runup Runup and the post-announcement-period announcement return AnnRet (i.e., Runup - AnnRet $<0$ ). The intuition behind this design is that there should be very little information leakage when the stock price goes up (down) before announcements with negative (positive) announcement returns. Therefore, the information-adjusted cumulative abnormal volume from the above orthogonalisation procedure for this particular subsample would be a cleaner proxy of liquidity trading than the one obtained for the full sample. It is useful to compare the results from empirical tests on the implications of liquidity trading using this subsample alone to the results using the full sample. If the two sets of empirical results are similar, it would mitigate the concern over the adequacy of the orthogonalisation procedure.

Second, we check the summary statistics regarding the raw cumulative abnormal trading volume before the orthogonalisation and the summary statistics regarding the information-adjusted cumulative abnormal trading volume after the orthogonalisation. Tables 4 and 5 present the summary statistics for the full sample and the special subsample, respectively. Based on the mean statistics, the raw cumulative abnormal trading volume is negative (positive) prior to the scheduled (unscheduled) announcements and the information-adjusted cumulative abnormal trading volume maintains the same sign as the raw volume. Moreover, untabulated results show that differences between the mean for scheduled announcements and the mean for unscheduled announcements are statistically significant at the $1 \%$ level. These patterns are qualitatively the same regardless of whether we use the full sample or the subsample with virtually no information leakage. These results confirm the decrease (increase) in the abnormal trading volume before scheduled (unscheduled) announcements, and thus entirely conform to the patterns in Figure 1. Overall, the evidence provided in Tables 4 and 5 lends support to the simple orthogonalisation procedure and confirms that the preannouncement-period liquidity trading is higher for unscheduled announcements than for the scheduled ones.

\subsection{Insider's decision to trade}

Having documented earlier that both the raw and information-adjusted cumulative abnormal trading volume drop (rise) prior to the scheduled (unscheduled) announcements, we now turn to insider responses to the varying extent of liquidity trading and empirically test the various hypotheses we developed in Section 2.

${ }^{22}$ We thank the anonymous referee for pointing out this concern. 
Table 4

Orthogonalisation of trading volume: full sample

This table presents the summary statistics of pre-announcement cumulative abnormal trading volume before and after the orthogonalisation procedure using all announcements. To carry out the orthogonalisation procedure, we first pool together all the announcements for each firm, and then regress the raw cumulative abnormal trading volume on stock price runup and announcement return associated with each announcement. The regression equation is:

$$
\text { Cumabvol }_{\text {raw }}=\beta_{0}+\beta_{1} \cdot \text { Runup }+\beta_{2} \cdot \text { AnnRet }+\epsilon,
$$

where Cumabvol $l_{\text {raw }}$ is the raw cumulative abnormal trading volume constructed as in Table 1. Runup and AnnRet are the absolute values of pre-announcement stock price runup proxying for informational leakage and announcement returns respectively. The above regression is estimated for each firm in the sample, and the information-adjusted cumulative abnormal trading volume is then obtained as the regression residuals. Panels A and B provide the summary statistics before and after the orthogonalisation procedure, respectively.

Panel A. Raw cumulative abnormal trading volume

\begin{tabular}{lcccccccc}
\hline & N & Min & Mean & P25 & Median & P75 & Max & Std \\
\hline Scheduled & 219058 & -71.494 & -0.155 & -3.737 & -0.278 & 3.207 & 81.408 & 6.322 \\
Unscheduled & 46117 & -52.817 & 0.114 & -3.683 & -0.092 & 3.559 & 86.305 & 6.664 \\
\hline
\end{tabular}

Panel B. Adjusted cumulative abnormal trading volume

\begin{tabular}{lcccccccc}
\hline & $\mathrm{N}$ & Min & Mean & P25 & Median & P75 & Max & Std \\
\hline Scheduled & 219058 & -69.423 & -0.021 & -3.348 & -0.051 & 3.226 & 66.331 & 5.775 \\
Unscheduled & 46117 & -49.110 & 0.101 & -3.357 & 0.038 & 3.416 & 71.798 & 6.026 \\
\hline
\end{tabular}

Hypothesis 1 concerns the influence of time-varying liquidity trading on the insider's propensity to trade prior to the scheduled and unscheduled announcements. To test Hypothesis 1, we use a logit regression to model insiders' decision to trade before corporate announcements. Since corporate insiders have private information about the valuation shock in the forthcoming announcements, they likely buy (sell) before positive (negative) news. Thus it appears reasonable to separate the analysis of the insider's propensity to buy stocks from that of the insider's propensity to sell stocks. Our choice of running the regressions separately for insider purchases and sales is also supported by the finding in the insider trading literature that insider purchases are more likely to be information driven than insider sales (Seyhun, 1986, 1988, 1998; Lakonishok and Lee, 2001; Jeng et al., 2003; Cohen et al., 2009; Lei et al., 2010).

Our regression specification is as follows:

$$
\begin{aligned}
\operatorname{Logit}\left(\frac{\operatorname{Prob}(\text { Buy }=1)}{1-\operatorname{Prob}(\text { Buy }=1)}\right)= & \beta_{0}+\beta_{1} \cdot \text { Runup }+\beta_{2} \cdot \text { Size }+\beta_{3} \cdot \text { AnnRet }+\beta_{4} \cdot \text { PastRet } \\
& +\beta_{5} \cdot \text { BM }+\beta_{6} \cdot \text { Cumabvol }+\beta_{7} \cdot \text { Cumabvolind }+\epsilon . \\
\operatorname{Logit}\left(\frac{\operatorname{Prob}(\text { Sell }=1)}{1-\operatorname{Prob}(\text { Sell }=1)}\right)= & \beta_{0}+\beta_{1} \cdot \text { Runup }+\beta_{2} \cdot \text { Size }+\beta_{3} \cdot \text { AnnRet }+\beta_{4} \cdot \text { PastRet } \\
& +\beta_{5} \cdot \text { BM }+\beta_{6} \cdot \text { Cumabvol }+\beta_{7} \cdot \text { Cumabvolind }+\epsilon .
\end{aligned}
$$

The dependent variables are the logit of an indicator variable that takes the value of one if there are insider purchases or sales within 30 days before the announcement and zero 
Table 5

Orthogonalisation of trading volume: subsample without information leakage

This table presents the summary statistics of pre-announcement cumulative abnormal trading volume before and after the orthogonalisation procedure using the announcements in the special subsample with Runup - AnnRet $<0$. To carry out the orthogonalisation procedure, we first pool together all the announcements for each firm, and then regress the raw cumulative abnormal trading volume on stock price runup and announcement return associated with each announcement. The regression equation is:

$$
\text { Cumabvol }_{\text {raw }}=\beta_{0}+\beta_{1} \cdot \text { Runup }+\beta_{2} \cdot \text { AnnRet }+\epsilon,
$$

where Cumabvol raw $_{\text {aw }}$ is the raw cumulative abnormal trading volume constructed as in Table 1. Runup and AnnRet are the absolute values of pre-announcement stock price runup proxying for informational leakage and announcement returns respectively. The above regression is estimated for each firm in the sample, and the information-adjusted cumulative abnormal trading volume is then obtained as the regression residuals. Panels A and B provide the summary statistics before and after the orthogonalisation procedure, respectively.

Panel A. Raw cumulative abnormal trading volume

\begin{tabular}{lcccccccc}
\hline & N & Min & Mean & P25 & Median & P75 & Max & Std \\
\hline Scheduled & 111017 & -71.494 & -0.028 & -3.619 & -0.182 & 3.302 & 71.476 & 6.333 \\
Unscheduled & 23969 & -52.817 & 0.099 & -3.662 & -0.070 & 3.590 & 78.865 & 6.684 \\
\hline
\end{tabular}

Panel B. Adjusted cumulative abnormal trading volume

\begin{tabular}{lcccccccc}
\hline & $\mathrm{N}$ & Min & Mean & P25 & Median & P75 & Max & Std \\
\hline Scheduled & 111017 & -59.816 & -0.004 & -3.075 & -0.043 & 2.998 & 49.073 & 5.374 \\
Unscheduled & 23969 & -47.930 & 0.020 & -3.156 & -0.013 & 3.129 & 55.406 & 5.555 \\
\hline
\end{tabular}

otherwise. The set of explanatory variables include a number of controls, Runup, Size, AnnRet, PastRet and BM that are defined in Section 3.

We include the firm size as a control because insiders in larger firms in general have more stock option grants and higher stock ownership than insiders in smaller firms, and hence, they are more likely to trade. An alternative justification is that there are more insiders in a large firm. Consequently, in a larger company it becomes more likely that at least one insider would choose to trade prior to the scheduled and/or unscheduled announcements. In other words, it is reasonable to expect a positive sign for Size in the logit regressions for the insider's propensity to buy as well as the insider's propensity to sell. It is important to include the recent stock return (PastRet) as a control in light of the finding in the extant literature that insiders are contrarian investors in general. Given the insiders' tendency to buy (sell) stocks following the recent decline (rise) in stock price, we expect PastRet has a negative (positive) sign for the insider probability to buy (sell). The information proxies include the price runup (Runup) in the pre-announcement period and the announcement return (AnnRet) that are designed to capture the potential information leakage and the informational content of the announcement, respectively. To the extent that insider purchases are driven by information reasons, insiders are more likely to buy when pre-announcement information leakage is small and when the announcement return is large. Consequently, we expect a negative (positive) sign before Runup (AnnRet) for the probability of insider purchases. For the probability of insider sales, the estimated effects of information proxies could be weaker because insider sales 
are less likely to be information-driven than insider purchases according to the existing findings in the literature.

The remaining two explanatory variables are the primary focus of the logit regressions, including the information-adjusted cumulative abnormal trading (Cumabvol) as well as an interaction term (Cumabvolind) between Cumabvol and an indicator variable that takes the value of one for unscheduled announcements and zero for scheduled announcements. Hypothesis 1 predicts that insiders are more likely to trade in the pre-announcement period as long as the volume of liquidity trading goes up. So the estimated coefficient for Cumabvol is expected to be positive for the insider's propensity to buy. Hypothesis 1 further predicts a stronger effect of liquidity trading on the insider's propensity to buy for unscheduled announcements than for scheduled ones. In other words, the estimated coefficient for the interaction term Cumabvolind is expected to be positive for the insider's propensity to buy. Again, the finding in the literature that insider sales are less likely to be information-driven implies potentially weaker effects for the insider's propensity to sell.

Each logit regression is first estimated separately for scheduled and unscheduled announcements, and then re-estimated using all announcements allowing for the interaction variable Cumabvolind. In one robustness check, we estimate each regression with and without firm fixed effects.

Consider first the results for the insider's propensity to buy in the pre-announcement period. Table 6 reports the results using the entire sample while Table 7 presents the results using the subsample presumably with little information leakage.

Our proxy for the extent of liquidity trading Cumabvol carries a positive and statistically significant estimate in both the full sample and the special subsample. In other words, the higher the pre-announcement liquidity trading, the more likely insiders will buy before announcements. Apparently, the estimated coefficient for Cumabvol is also reliably higher for the unscheduled announcements than the scheduled announcements regardless of the specification. This stronger effect of liquidity trading on the insider's propensity to buy in the pre-unscheduled-announcement period than in the pre-scheduled-announcement period is also reflected by the positive and statistically significant coefficient for the interaction term Cumabvolind.

Among the set of control variables, the size effect and the effect of past returns are the strongest in terms of consistency across different regression designs and statistical significance. As expected, the size effect is positive, reflecting the higher likelihood of insider purchases prior to announcements of either type due to the larger number of insiders present in a large company. The consistently negative coefficient in front of past return (PastRet), which is also statistically significant at the $1 \%$ level for all designs, well reflects insiders as contrarian investors in general.

The fact that both Cumabvol and Cumabvolind are positive and significant at the $1 \%$ level in all regression designs echoes well with both predictions in Hypothesis 1 . Moreover, we find empirical support for these two predictions in both the full sample and the special subsample without information leakage, even though the effects using the subsample are understandably smaller in magnitude. The survival of the main empirical findings in the specially designed subsample thus validates the usefulness of the information-adjusted cumulative abnormal return as a proxy for the extent of liquidity trading. Overall, the results in Tables 6 and 7 lend strong empirical support to Hypothesis 1.

Turning to the regressions for the insider's probability to sell in the pre-announcement period, the results in Tables 8 and 9 show that the size effect and the effect of past 
Table 6

Insider's decision to buy: full sample

This table presents the insider's decision to buy before corporate announcements using the full sample. The dependent variable is the logit of an indicator variable that takes the value of one if there are insider purchases within thirty days before the announcement and zero otherwise. Cumabvol is informationadjusted cumulative abnormal trading volume; Runup, Size, AnnRet, PastRet and BM are defined in Table 1. Cumabvolind is the interaction term between Cumabvol and an indicator variable that takes the value of one for unscheduled announcements and zero for scheduled announcements. The logistic regression equation is specified as follows:

$$
\begin{aligned}
\operatorname{Logit}\left(\frac{\operatorname{Prob}(\text { Buy }=1)}{1-\operatorname{Prob}(\text { Buy }=1)}\right)= & \beta_{0}+\beta_{1} \cdot \text { Runup }+\beta_{2} \cdot \text { Size }+\beta_{3} \cdot \text { AnnRet }+\beta_{4} \cdot \text { PastRet } \\
& +\beta_{5} \cdot \text { BM }+\beta_{6} \cdot \text { Cumabvol }+\beta_{7} \cdot \text { Cumabvolind }+\epsilon .
\end{aligned}
$$

The first four columns estimate the regression equation for scheduled and unscheduled announcements separately. The last two columns pool together the scheduled and unscheduled announcements and re-estimate the regression equation augmented with the interaction term Cumabvolind. The $P$-values are reported in parentheses. ${ }^{* * *},{ }^{* *}$ and ${ }^{*}$ denote statistical significance at the 1 percent, 5 percent and 10 percent level respectively.

\begin{tabular}{lcccccc}
\hline & \multicolumn{2}{c}{ Scheduled } & \multicolumn{2}{c}{ Unscheduled } & \multicolumn{2}{c}{ All } \\
\hline Intercept & $-3.618^{* * *}$ & & $-3.991^{* * *}$ & & $-3.862^{* * *}$ \\
& $(0.001)$ & & $(0.001)$ & & $(0.001)$ & \\
Runup & $-0.211^{* *}$ & -0.066 & $-1.112^{* * *}$ & $-0.725^{* * *}$ & $-0.402^{* * *}$ & $-0.273^{* * *}$ \\
& $(0.010)$ & $(0.479)$ & $(0.001)$ & $(0.001)$ & $(0.001)$ & $(0.001)$ \\
Size & $0.014^{* *}$ & $0.193^{* * *}$ & $0.086^{* * *}$ & $0.566^{* * *}$ & $0.042^{* * *}$ & $0.270^{* * *}$ \\
& $(0.032)$ & $(0.001)$ & $(0.001)$ & $(0.001)$ & $(0.001)$ & $(0.001)$ \\
AnnRet & $0.308^{* *}$ & $0.601^{* * *}$ & -0.316 & 0.334 & $0.305^{* * *}$ & $0.636^{* * *}$ \\
& $(0.025)$ & $(0.001)$ & $(0.177)$ & $(0.269)$ & $(0.008)$ & $(0.001)$ \\
PastRet & $-0.399^{* * *}$ & $-0.522^{* * *}$ & $-0.660^{* * *}$ & $-0.825^{* * *}$ & $-0.447^{* * *}$ & $-0.591^{* * *}$ \\
& $(0.001)$ & $(0.001)$ & $(0.001)$ & $(0.001)$ & $(0.001)$ & $(0.001)$ \\
BM & $-0.006^{* * *}$ & -0.001 & $-0.009^{* * *}$ & $0.093^{* *}$ & $-0.006^{* * *}$ & -0.001 \\
& $(0.001)$ & $(0.481)$ & $(0.009)$ & $(0.012)$ & $(0.001)$ & $(0.564)$ \\
Cumabvol & $0.014^{* * *}$ & $0.022^{* * *}$ & $0.020^{* * *}$ & $0.029^{* * *}$ & $0.010^{* * *}$ & $0.017^{* * *}$ \\
& $(0.001)$ & $(0.001)$ & $(0.001)$ & $(0.001)$ & $(0.001)$ & $(0.001)$ \\
Cumabvolind & & & & & $0.027^{* * *}$ & $0.033^{* * *}$ \\
& & & & & $(0.001)$ & $(0.001)$ \\
Fixed effects & No & Yes & No & Yes & No & Yes \\
\hline
\end{tabular}

returns continue to stand out as the most important control variables with expected signs and statistical significance at the $1 \%$ level for all designs. Interestingly, the estimated coefficients for our focal variable Cumabvol are positive and highly statistically significant only for scheduled announcements. This is true for all regression designs including the full sample and the specially designed subsample, providing empirical support for Hypothesis 1 in that the drop in the amount of liquidity trading in the period prior to scheduled announcements naturally dampens the insider's propensity to sell. Nevertheless, the lack of strong statistical evidence surrounding unscheduled announcements, as far as the insider's propensity to sell is concerned, speaks to the finding in the literature that insiders sales before corporate announcements are less likely to be information-driven than insider purchases. 
Table 7

Insider's decision to buy: subsample without information leakage

This table presents the insider's decision to buy before corporate announcements using the subsample with Runup - AnnRet $<0$. The dependent variable is the logit of an indicator variable that takes the value of one if there are insider purchases within thirty days before the announcement and zero otherwise. Cumabvol is information-adjusted cumulative abnormal trading volume; Runup, Size, AnnRet, PastRet and $B M$ are defined in Table 1. Cumabvolind is the interaction term between Cumabvol and an indicator variable that takes the value of one for unscheduled announcements and zero for scheduled announcements. The logistic regression equation is specified as follows:

$$
\begin{aligned}
\operatorname{Logit}\left(\frac{\operatorname{Prob}(\text { Buy }=1)}{1-\operatorname{Prob}(\text { Buy }=1)}\right)= & \beta_{0}+\beta_{1} \cdot \text { Runup }+\beta_{2} \cdot \text { Size }+\beta_{3} \cdot \text { AnnRet }+\beta_{4} \cdot \text { PastRet } \\
& +\beta_{5} \cdot \text { BM }+\beta_{6} \cdot \text { Cumabvol }+\beta_{7} \cdot \text { Cumabvolind }+\epsilon .
\end{aligned}
$$

The first four columns estimate the regression equation for scheduled and unscheduled announcements separately. The last two columns pool together the scheduled and unscheduled announcements and re-estimate the regression equation augmented with the interaction term Cumabvolind. The $P$-values are reported in parentheses. ${ }^{* * *},{ }^{* *}$ and ${ }^{*}$ denote statistical significance at the 1 percent, 5 percent and 10 percent level respectively.

\begin{tabular}{lcccccc}
\hline & \multicolumn{2}{c}{ Scheduled } & \multicolumn{2}{c}{ Unscheduled } & \multicolumn{2}{c}{ All } \\
\hline Intercept & $-3.495^{* * *}$ & & $-3.754^{* * *}$ & & $-3.716^{* * *}$ \\
& $(0.001)$ & & $(0.001)$ & & $(0.001)$ \\
Runup & $-0.264^{*}$ & 0.030 & $-1.769^{* * *}$ & $-1.271^{* * *}$ & $-0.608^{* * *}$ & $-0.294^{*}$ \\
& $(0.074)$ & $(0.855)$ & $(0.001)$ & $(0.001)$ & $(0.001)$ & $(0.054)$ \\
Size & 0.007 & $0.205^{* * *}$ & $0.071^{* * *}$ & $0.626^{* * *}$ & $0.034^{* * *}$ & $0.276^{* * *}$ \\
& $(0.472)$ & $(0.001)$ & $(0.001)$ & $(0.001)$ & $(0.001)$ & $(0.001)$ \\
AnnRet & 0.250 & $0.911^{* * *}$ & $-1.060^{* *}$ & -0.182 & 0.053 & $0.839^{* * *}$ \\
& $(0.330)$ & $(0.001)$ & $(0.016)$ & $(0.784)$ & $(0.805)$ & $(0.001)$ \\
PastRet & $-0.531^{* * *}$ & $-0.666^{* * *}$ & $-0.890^{* * *}$ & $-1.063^{* * *}$ & $-0.603^{* * *}$ & $-0.761^{* * *}$ \\
& $(0.001)$ & $(0.001)$ & $(0.001)$ & $(0.001)$ & $(0.001)$ & $(0.001)$ \\
BM & $-0.032^{* * *}$ & 0.037 & $-0.019^{*}$ & $0.226^{* *}$ & $-0.030^{* * *}$ & 0.024 \\
& $(0.001)$ & $(0.174)$ & $(0.066)$ & $(0.020)$ & $(0.001)$ & $(0.280)$ \\
Cumabvol & $0.010^{* * *}$ & $0.017^{* * *}$ & $0.018^{* * *}$ & $0.023^{* * *}$ & $0.006^{* *}$ & $0.012^{* * *}$ \\
\multirow{4}{*}{ Cumabvolind } & $(0.001)$ & $(0.001)$ & $(0.001)$ & $(0.001)$ & $(0.016)$ & $(0.001)$ \\
& & & & & $0.031^{* * *}$ & $0.033^{* * *}$ \\
Fixed Effects & No & Yes & No & Yes & $(0.001)$ & $(0.001)$ \\
& & & & No & Yes \\
\hline
\end{tabular}

\subsection{Insider's direction of trade}

We now examine the implications on insiders' direction of trade prior to the corporate announcements. Hypothesis 2 posits that insiders' trading direction should be associated with the informational content of announcements, with a stronger effect for unscheduled announcements than for scheduled announcements. To test this hypothesis, we work with the sub-sample of corporate announcements before which there were insider trades. Our regression equation for this test is:

$$
\begin{aligned}
\text { InsTrd }= & \beta_{0}+\beta_{1} \cdot \text { Runup }+\beta_{2} \cdot \text { Size }+\beta_{3} \cdot \text { PastRet }+\beta_{4} \cdot \text { BM } \\
& +\beta_{5} \cdot \text { AnnRet }+\beta_{6} \cdot \text { AnnRetInd }+\epsilon .
\end{aligned}
$$


Table 8

Insider's decision to sell: full sample

This table presents the insider's decision to sell before corporate announcements using the full sample. The dependent variable is the logit of an indicator variable that takes the value of one if there are insider sales within thirty days before the announcement and zero otherwise. Cumabvol is information-adjusted cumulative abnormal trading volume; Runup, Size, AnnRet, PastRet and BMare defined in Table 1. Cumabvolind is the interaction term between Cumabvol and an indicator variable that takes the value of one for unscheduled announcements and zero for scheduled announcements. The logistic regression equation is specified as follows:

$$
\begin{aligned}
\operatorname{Logit}\left(\frac{\operatorname{Prob}(\text { Sell }=1)}{1-\operatorname{Prob}(\text { Sell }=1)}\right)= & \beta_{0}+\beta_{1} \cdot \text { Runup }+\beta_{2} \cdot \text { Size }+\beta_{3} \cdot \text { AnnRet }+\beta_{4} \cdot \text { PastRet } \\
& +\beta_{5} \cdot B M+\beta_{6} \cdot \text { Cumabvol }+\beta_{7} \cdot \text { Cumabvolind }+\epsilon .
\end{aligned}
$$

The first four columns estimate the regression equation for scheduled and unscheduled announcements separately. The last two columns pool together the scheduled and unscheduled announcements and re-estimate the regression equation augmented with the interaction term Cumabvolind. The $P$-values are reported in parentheses. ${ }^{* * *},{ }^{*}$ and ${ }^{*}$ denote statistical significance at the 1 percent, 5 percent and 10 percent level respectively.

\begin{tabular}{lcccccc}
\hline & \multicolumn{2}{c}{ Scheduled } & \multicolumn{2}{c}{ Unscheduled } & \multicolumn{2}{c}{ All } \\
\hline Intercept & $-6.595^{* * *}$ & & $-7.062^{* * *}$ & & $-6.850^{* * *}$ \\
& $(0.001)$ & & $(0.001)$ & & $(0.001)$ & \\
Runup & $0.647^{* * *}$ & $1.042^{* * *}$ & $0.650^{* * *}$ & $1.624^{* * *}$ & $0.657^{* * *}$ & $1.067^{* * *}$ \\
& $(0.001)$ & $(0.001)$ & $(0.001)$ & $(0.001)$ & $(0.001)$ & $(0.001)$ \\
Size & $0.289^{* * *}$ & $0.910^{* * *}$ & $0.364^{* * *}$ & $1.225^{* * *}$ & $0.317^{* * *}$ & $0.939^{* * *}$ \\
& $(0.001)$ & $(0.001)$ & $(0.001)$ & $(0.001)$ & $(0.001)$ & $(0.001)$ \\
AnnRet & 0.009 & $0.273^{* *}$ & $-0.743^{* * *}$ & $-0.564^{*}$ & -0.023 & $0.280^{* * *}$ \\
\multirow{4}{*}{ PastRet } & $(0.938)$ & $(0.027)$ & $(0.001)$ & $(0.060)$ & $(0.827)$ & $(0.001)$ \\
& $0.340^{* * *}$ & $0.275^{* * *}$ & $0.281^{* * *}$ & $0.263^{* * *}$ & $0.3344^{* * *}$ & $0.262^{* * *}$ \\
BM & $(0.001)$ & $(0.001)$ & $(0.001)$ & $(0.001)$ & $(0.001)$ & $(0.001)$ \\
& $-0.010^{* * *}$ & -0.006 & $-0.024^{* * *}$ & -0.009 & $-0.013^{* * *}$ & $-0.007^{* *}$ \\
Cumabvol & $(0.001)$ & $(0.131)$ & $(0.001)$ & $(0.635)$ & $(0.001)$ & $(0.028)$ \\
& $0.015^{* * *}$ & $0.015^{* * *}$ & -0.001 & 0.0002 & $0.011^{* * *}$ & $0.009^{* * *}$ \\
Cumabvolind & $(0.001)$ & $(0.001)$ & $(0.717)$ & $(0.943)$ & $(0.001)$ & $(0.001)$ \\
& & & & & -0.002 & 0.005 \\
Fixed Effects & No & Yes & No & Yes & $(0.490)$ & $(0.163)$ \\
& & & & & No & Yes \\
\hline
\end{tabular}

The dependent variable InsTrd is a measure of insider trading intensity defined as the difference between the dollar value of insider purchases and sales scaled by the total dollar value of insider purchases and sales before each announcement. ${ }^{23}$ The set of explanatory variables include the five control variables in the logit regressions discussed earlier, Runup, Size, AnnRet, PastRet and BM. Also included as part of the explanatory variables

\footnotetext{
${ }^{23}$ Our design for the dependent variable is consistent with the insider trading literature. For instance, Garfinkel (1997) and Huddart et al. (2007) use the same measure for the insider trading intensity. We also perform one robustness check by defining the insider trading intensity in terms of number of trades. The empirical results remain qualitatively the same.
} 
Table 9

Insider's decision to sell: subsample without informational leakage

This table presents the insider's decision to sell before corporate announcements using the subsample with Runup. Ann Ret $<0$. The dependent variable is the logit of an indicator variable that takes the value of one if there are insider sales within thirty days before the announcement and zero otherwise. Cumabvol is information-adjusted cumulative abnormal trading volume; Runup, Size, AnnRet, PastRet and BMare defined in Table 1. Cumabvolind is the interaction term between Cumabvol and an indicator variable that takes the value of one for unscheduled announcements and zero for scheduled announcements. The logistic regression equation is specified as follows:

$$
\begin{aligned}
\operatorname{Logit}\left(\frac{\operatorname{Prob}(\text { Sell }=1)}{1-\operatorname{Prob}(\text { Sell }=1)}\right)= & \beta_{0}+\beta_{1} \cdot \text { Runup }+\beta_{2} \cdot \text { Size }+\beta_{3} \cdot \text { AnnRet }+\beta_{4} \cdot \text { PastRet } \\
& +\beta_{5} \cdot \text { BM }+\beta_{6} \cdot \text { Cumabvol }+\beta_{7} \cdot \text { Cumabvolind }+\epsilon .
\end{aligned}
$$

The first four columns estimate the regression equation for scheduled and unscheduled announcements separately. The last two columns pool together the scheduled and unscheduled announcements and re-estimate the regression equation augmented with the interaction term Cumabvolind. The p-values are reported in parentheses. ${ }^{* * *},{ }^{* *}$ and ${ }^{*}$ denote statistical significance at the 1 percent, 5 percent and 10 percent level respectively.

\begin{tabular}{lcccccc}
\hline & \multicolumn{2}{c}{ Scheduled } & \multicolumn{2}{c}{ Unscheduled } & \multicolumn{2}{c}{ All } \\
\hline Intercept & $-6.551^{* * *}$ & & $-6.734^{* * *}$ & & $-6.756^{* * *}$ \\
& $(0.001)$ & & $(0.001)$ & & $(0.001)$ & \\
Runup & $0.680^{* * *}$ & $1.151^{* * *}$ & 0.294 & $1.445^{* * *}$ & $0.600^{* * *}$ & $1.140^{* * *}$ \\
& $(0.001)$ & $(0.001)$ & $(0.158)$ & $(0.001)$ & $(0.001)$ & $(0.001)$ \\
Size & $0.288^{* * *}$ & $0.933^{* * *}$ & $0.341^{* * *}$ & $1.179^{* * *}$ & $0.312^{* * *}$ & $0.949^{* * *}$ \\
& $(0.001)$ & $(0.001)$ & $(0.001)$ & $(0.001)$ & $(0.001)$ & $(0.001)$ \\
AnnRet & -0.206 & 0.088 & $-1.775^{* * *}$ & $-2.137^{* * *}$ & $-0.412^{* *}$ & -0.098 \\
\multirow{4}{*}{ PastRet } & $(0.354)$ & $(0.714)$ & $(0.001)$ & $(0.001)$ & $(0.034)$ & $(0.640)$ \\
& $0.415^{* * *}$ & $0.340^{* * *}$ & $0.343^{* * *}$ & $0.495^{* * *}$ & 0.404 \\
BM & $(0.001)$ & $(0.001)$ & $(0.001)$ & $(0.001)$ & $(0.001)$ & $\left(0.343^{* * *}\right.$ \\
& $-0.105^{* * *}$ & $-0.048^{* * *}$ & $-0.062^{* * *}$ & -0.049 & $-0.095^{* * *}$ & $-0.053^{* * *}$ \\
Cumabvol & $(0.001)$ & $(0.001)$ & $(0.001)$ & $(0.171)$ & $(0.001)$ & $(0.001)$ \\
& $0.006^{* * *}$ & $0.007^{* * *}$ & -0.002 & -0.002 & 0.003 & 0.002 \\
Cumabvolind & $(0.001)$ & $(0.001)$ & $(0.532)$ & $(0.695)$ & $(0.170)$ & $(0.483)$ \\
& & & & & 0.005 & $0.009^{*}$ \\
Fixed Effects & No & Yes & No & Yes & No & Yes \\
\hline
\end{tabular}

is AnnRetInd, which is an interaction term between the announcement return AnnRet and an indicator variable that takes the value of one for unscheduled announcements and zero for scheduled announcements.

In this empirical test, we primarily focus on two variables - AnnRet and AnnRetInd. Hypothesis 2 predicts that there exists a positive relationship between insiders' signed volume and the information content of the announcements. Consequently we expect a positive coefficient for AnnRet. Hypothesis 2 also predicts that the positive relationship should be stronger for unscheduled announcements than for scheduled ones. In other words, the estimated coefficient for the interaction term AnnRetInd is expected to be positive as well. 
Table 10

Insider's direction of trade

This table presents the insider's direction of trade prior to corporate announcements using a multivariate regression framework. The regression equation is specified as follows:

InsTrd $=\beta_{0}+\beta_{1} \cdot$ Runup $+\beta_{2} \cdot$ Size $+\beta_{3} \cdot$ PastRet $+\beta_{4} \cdot B M+\beta_{5} \cdot$ AnnRet $+\beta_{6} \cdot$ AnnRetInd $+\epsilon$.

The dependent variable InsTrd is defined as the difference between dollar value of pre-announcement insider purchases and sales scaled by the total dollar value of pre-announcement insider trades. An insider trade is defined as pre-announcement trade if the trade takes place within thirty days before the announcement date. Runup, Size, AnnRet, PastRet and BM are defined in Table 1. AnnRetInd is the interaction term between AnnRet and an indicator variable that takes the value of one for unscheduled announcements and zero for scheduled announcements. The first four columns estimate the regression equation for scheduled and unscheduled announcements separately. The last two columns pool together the scheduled and unscheduled announcements and re-estimate the regression equation augmented with the interaction term AnnRetInd. The P-values are reported in parentheses. ${ }^{* * *}{ }^{* *}$ and ${ }^{*}$ denote statistical significance at the 1 percent, 5 percent and 10 percent level respectively.

\begin{tabular}{lcccccc}
\hline \hline & \multicolumn{2}{c}{ Scheduled } & \multicolumn{2}{c}{ Unscheduled } & \multicolumn{2}{c}{ All } \\
\hline Intercept & $1.635^{* * *}$ & & $1.279^{* * *}$ & & $1.611^{* * *}$ \\
& $(0.001)$ & & $(0.001)$ & & $(0.001)$ & \\
Runup & $-0.338^{* * *}$ & $-0.325^{* * *}$ & $-0.490^{* * *}$ & $-0.551^{* * *}$ & $-0.402^{* * *}$ & $-0.428^{* * *}$ \\
& $(0.001)$ & $(0.001)$ & $(0.001)$ & $(0.001)$ & $(0.001)$ & $(0.001)$ \\
Size & $-0.147^{* * *}$ & $-0.286^{* * *}$ & $-0.126^{* * *}$ & $-0.218^{* * *}$ & $-0.144^{* * *}$ & $-0.277^{* * *}$ \\
& $(0.001)$ & $(0.001)$ & $(0.001)$ & $(0.001)$ & $(0.001)$ & $(0.001)$ \\
PastRet & $-0.270^{* * *}$ & $-0.148^{* * *}$ & $-0.302^{* * *}$ & $-0.228^{* * *}$ & $-0.287^{* * *}$ & $-0.178^{* * *}$ \\
& $(0.001)$ & $(0.001)$ & $(0.001)$ & $(0.001)$ & $(0.001)$ & $(0.001)$ \\
BM & 0.000 & 0.000 & $0.223^{* * *}$ & $0.152^{* * *}$ & 0.001 & 0.001 \\
& $(0.682)$ & $(0.310)$ & $(0.001)$ & $(0.001)$ & $(0.417)$ & $(0.260)$ \\
AnnRet & $0.164^{* *}$ & 0.041 & $0.318^{* * *}$ & $0.341^{*}$ & $0.156^{* *}$ & 0.010 \\
& $(0.024)$ & $(0.556)$ & $(0.001)$ & $(0.079)$ & $(0.030)$ & $(0.886)$ \\
AnnRetInd & & & & & 0.166 & $0.358^{* *}$ \\
& & & & & $(0.232)$ & $(0.011)$ \\
Fixed Effects & No & Yes & No & Yes & No & Yes \\
\hline
\end{tabular}

We first estimate the regression separately for the scheduled and unscheduled announcements excluding the interaction term, with and without firm fixed effects. The first four columns of Table 10 provide the estimation results. We then estimate the regression with the interaction term after pooling together both types of announcements and report the results in the last two columns of Table 10. Three of the control variables stand out in that all regression designs lead to a persistently negative coefficient for Runup, Size and PastRet, all of which are statistically significant at the $1 \%$ level. The negative effect of the price runup suggests that insiders buy more in the presence of little information leakage in the pre-announcement period. The size effect is consistent with the dominance of insider sales over insider purchases among large firms. The negative coefficient for the past returns once again points to the fact that insiders are contrarian investors in general, buying more after stock falls and selling more after stock rises.

More importantly, we notice that the announcement return AnnRet indeed carries positive signs for both scheduled and unscheduled announcements, although the statistical significance is weaker in the regressions with firm fixed effects. The estimated 
coefficient for the positive effect is also larger among unscheduled announcements than scheduled announcements, as Hypothesis 2 suggests. Therefore, insiders' trading direction appears broadly in line with the informational content of the announcements in our sample, a finding consistent with Huddart et al. (2007) who also document a positive but weak relationship between the pre-announcement insider trading and announcement returns.

Given the observed larger estimate for AnnRet among the unscheduled announcements than the scheduled announcements, it is not surprising to find a positive coefficient for the interaction term AnnRetInd in the last two columns of results in Table 10 after pooling together both types of announcements. Moreover, the insignificant AnnRetInd becomes significant at the 5\% level once we control for firm fixed effects. Overall, the results in Table 10 lend somewhat weak support to Hypothesis 2.

\subsection{Profitability of insider purchases}

So far our empirical exercises have dealt with the insider's decision to trade and the insider's direction of trade prior to corporate announcements. We now turn to examining the performance of insider trades during the pre-announcement period. The profitability analysis of insider trades complements the previous tests and provides further insights into insiders' trading patterns. Given that insider purchases are more likely to be information-driven than insider sales in general, we focus on insider purchases when examining the profitability of insider trades.

When assessing the profitability of insider trades, ideally we would like to know when insiders liquidate their established positions. This is almost impossible though because insiders are not obligated to report such information when filing with the SEC. Consequently researchers have some freedom in choosing the specific time span during which to cumulate stock returns. This choice involves a non-trivial set of trade-offs. Choosing a too long horizon could subject the profitability measure to the contamination of information events that follow the announcement in question. Too short a horizon, on the other hand, may not fully capture the informational effects of the announcement events. In this study, we choose a 30-day window right after insider trades as the time horizon over which we measure the profitability of insider trades. This seems to be a reasonable compromise given that quarterly earnings announcements are successive and three months apart. This choice is also consistent with how we define the event window prior to the announcements in earlier tests.

To measure the profitability of insider trades, we first calculate the abnormal stock return for each insider trade. More specifically, for each announcement event we estimate a market model using stock returns over $[t-210, t-31]$, where $t$ is the announcement date. Daily abnormal return during the 30-day window after the date of each insider trade is then calculated by subtracting the predicted return using the market model parameters from the daily stock return. Daily abnormal returns are then cumulated and averaged across all trades for each event using either the equal-weighting or value-weighting scheme. The average cumulative abnormal return in the subsequent 30-day holding period is $1.8 \%$ for insider purchases prior to scheduled announcements and $4.2 \%$ for insider purchases prior to unscheduled announcements.

That the insider purchases are profitable in the immediate 30-day period is hardly surprising. After all, the insider trading literature has documented that insider purchases on average are followed by positive abnormal stock returns. Stock prices go up after 
insiders buy before both scheduled and unscheduled announcements. It is remarkable though insider purchases before unscheduled announcements are much more profitable than those before scheduled announcements. In fact, the average cumulative abnormal returns for insider purchases before unscheduled announcements more than double that for insider purchases before scheduled announcements, with the difference in mean statistically significant at the $1 \%$ level. Thus, it appears that the analysis of the mean profit over the 30-day period following the insider trades provides strong supportive evidence for Hypothesis 3.

The univariate results can be misleading, however, because it does not consider other factors that may affect the relative profitability of insider purchases before scheduled versus unscheduled announcements. For instance, the extent of valuation shocks behind each announcement could be vastly different among different types of announcements. It would be useful to conduct a multivariate regression analysis to properly control for variables that are known to affect the analysis of relative profitability. We run the following regression at the event level:

$$
\begin{aligned}
\text { Abret }= & \beta_{0}+\beta_{1} \cdot \text { Runup }+\beta_{2} \cdot \text { Size }+\beta_{3} \cdot \text { PastRet }+\beta_{4} \cdot \text { BM } \\
& +\beta_{5} \cdot \text { AnnRet }+\beta_{6} \cdot \text { Is Unscheduled }+\epsilon,
\end{aligned}
$$

where the dependent variable Abret is the (equal-weighted or value-weighted) average cumulative abnormal stock returns. In addition to the usual set of five control variables, the set of explanatory variables also includes an indicator variable Is Unscheduled that takes the value of one for unscheduled announcements and zero for scheduled announcements.

Three of the control variables stand out of the results reported in Table 11. Both the price runup and the announcement returns have an estimated coefficient that is reliably positive across all regression designs with both equal-weighting and valueweighting. These two positive associations with the profit of insider purchases are not surprising at all. Given an announcement in day $t$, the price runup is defined over $[t-30, t-2]$, and the announcement return is defined over $[t-1, t+1]$. Because the insider transaction date is inside the pre-announcement period $[t-30, t-1]$, the insider return during the 30-day holding period necessarily overlaps with both the price runup and the announcement return, leading to the two strongly positive associations. The past return is negatively related to the profitability of insider purchases, statistically significant at the $1 \%$ level for all regression designs. This finding is once again consistent with the literature that suggests insiders as contrarian investors in general (Rozeff and Zaman, 1998).

Our main focus in this exercise is to examine the relative profitability of insider purchases between the two types of announcements once the competing effects are controlled for. In the design without the indicator variable, the estimated intercept for the unscheduled announcements is clearly higher than that for the scheduled announcements. This higher profitability among unscheduled announcements is further verified in the regression design with the indicator variable. The outperformance of the insider purchases prior to unscheduled announcements related to the insider purchases prior to scheduled announcements amounts to 77 basis points with statistical significance at the $5 \%$ level with equal-weighting. Under the value-weighting scheme, the outperformance is 81 basis points with statistical significance at the $1 \%$ level.

In sum, we present evidence that the insider purchases prior to the unscheduled announcements are more profitable than the insider purchases prior to the scheduled 
Table 11

Profitability of insider purchases

This table presents the results of regression analysis on the profitability of insider purchases before corporate announcements. The regression equation is specified as follows:

Abret $=\beta_{0}+\beta_{1} \cdot$ Runup $+\beta_{2} \cdot$ Size $+\beta_{3} \cdot$ PastRet $+\beta_{4} \cdot B M+\beta_{5} \cdot$ AnnRet $+\beta_{6} \cdot$ Is Uncheduled $+\epsilon$.

Abret is the weighted average abnormal return of insider trades before announcement events. Runup, Size, AnnRet, PastRet and BM are defined in Table 1. IsUncheduled is an indicator variable that takes the value of one for unscheduled announcements and zero for scheduled ones. The P-values are reported in parentheses. ${ }^{* * *},{ }^{* *}$ and ${ }^{*}$ denote statistical significance at the 1 percent, 5 percent and 10 percent level respectively.

\begin{tabular}{|c|c|c|c|c|c|c|}
\hline & \multicolumn{2}{|c|}{ Scheduled } & \multicolumn{2}{|c|}{ Unscheduled } & \multicolumn{2}{|c|}{ All } \\
\hline & EW & VW & EW & VW & EW & VW \\
\hline Intercept & $\begin{array}{c}0.027^{* *} \\
(0.013)\end{array}$ & $\begin{array}{l}0.029^{* * *} \\
(0.009)\end{array}$ & $\begin{array}{r}0.035^{*} \\
(0.066)\end{array}$ & $\begin{array}{l}0.037^{* *} \\
(0.048)\end{array}$ & $\begin{array}{l}0.027^{* * *} \\
(0.003)\end{array}$ & $\begin{array}{l}0.029^{* * *} \\
(0.002)\end{array}$ \\
\hline Runup & $\begin{array}{l}0.429^{* * *} \\
(0.001)\end{array}$ & $\begin{array}{l}0.429^{* * *} \\
(0.001)\end{array}$ & $\begin{array}{l}0.407^{* * *} \\
(0.001)\end{array}$ & $\begin{array}{l}0.412^{* * *} \\
(0.001)\end{array}$ & $\begin{array}{l}0.424^{* * *} \\
(0.001)\end{array}$ & $\begin{array}{l}0.425^{* * *} \\
(0.001)\end{array}$ \\
\hline Size & $\begin{array}{c}-0.419 \\
(0.628)\end{array}$ & $\begin{array}{c}-0.504 \\
(0.564)\end{array}$ & $\begin{array}{c}-0.426 \\
(0.753)\end{array}$ & $\begin{array}{c}-0.547 \\
(0.686)\end{array}$ & $\begin{array}{c}-0.435 \\
(0.543)\end{array}$ & $\begin{array}{c}-0.534 \\
(0.461)\end{array}$ \\
\hline PastRet & $\begin{array}{c}-0.074^{* * *} \\
(0.001)\end{array}$ & $\begin{array}{c}-0.076^{* * *} \\
(0.001)\end{array}$ & $\begin{array}{c}-0.075^{* * *} \\
(0.001)\end{array}$ & $\begin{array}{c}-0.076^{* * *} \\
(0.001)\end{array}$ & $\begin{array}{c}-0.074^{* * *} \\
(0.001)\end{array}$ & $\begin{array}{c}-0.076^{* * *} \\
(0.001)\end{array}$ \\
\hline$B M$ & $\begin{array}{c}-0.001 \\
(0.304)\end{array}$ & $\begin{array}{c}-0.001 \\
(0.311)\end{array}$ & $\begin{array}{c}-0.001 \\
(0.853)\end{array}$ & $\begin{array}{c}-0.001 \\
(0.827)\end{array}$ & $\begin{array}{c}-0.001 \\
(0.325)\end{array}$ & $\begin{array}{c}-0.001 \\
(0.330)\end{array}$ \\
\hline AnnRet & $\begin{array}{l}0.824^{* * *} \\
(0.001)\end{array}$ & $\begin{array}{l}0.818^{* * *} \\
(0.001)\end{array}$ & $\begin{array}{l}0.840^{* * *} \\
(0.001)\end{array}$ & $\begin{array}{l}0.840^{* * *} \\
(0.001)\end{array}$ & $\begin{array}{l}0.830^{* * *} \\
(0.001)\end{array}$ & $\begin{array}{l}0.826^{* * *} \\
(0.001)\end{array}$ \\
\hline Is Unscheduled & & & & & $\begin{array}{c}0.008^{* *} \\
(0.012)\end{array}$ & $\begin{array}{l}0.008^{* * *} \\
(0.009)\end{array}$ \\
\hline
\end{tabular}

announcements and this superior performance exists not only in raw univariate analysis but also after we control for competing factors in a multivariate regression setting. These findings strongly support Hypothesis 3.

\section{Conclusions}

This paper examines the strategic implications of time-varying liquidity trading before two types of corporate announcements. While the dates of scheduled announcements are predictable in advance, those of unscheduled announcements are not. This difference directly results in a distinctive drop in the amount of liquidity trading in the preannouncement period prior to the scheduled announcements, but not so prior to the unscheduled announcements. Consequently, the informed traders should prefer submitting orders prior to the unscheduled announcements as opposed to the scheduled announcements given the better camouflage in the former context. By investigating how corporate insiders (as a proxy for informed traders) respond to the time variation in the amount of liquidity trading prior to these two types of corporate announcements, our paper essentially provides an empirical test of the strategic trading model in the literature. We demonstrate in this paper that insiders indeed behave strategically in response to 
the time-variation in the amount of liquidity trading. Therefore, findings in this paper deepen our understanding of the interactions between informed traders and liquidity traders.

Given our primary focus on insiders' trading patterns before the two types of corporate announcements, this paper is also related to the insider trading literature. It is quite natural to use insider trades in an empirical test of the strategic trading model because the actual trades of informed traders are rarely disclosed, nor are they explicitly observed in reality. Our paper complements the insider trade timing literature as we document direct evidence that insiders time their trades before corporate announcements based on the amount of liquidity trading that is available to cover their trades.

Despite our contribution to the strategic trading literature as well as the insider trading literature, we should remind readers of the data limitations inherent in such an empirical study. For instance, this paper does not illustrate the exact mechanism of trade camouflage from a market microstructure viewpoint even though we have extensively relied on the notion of camouflage to motivate the insider decisions over the timing of their trades. An anatomy of the trading process to uncover the underlying mechanism of camouflage would greatly strengthen our understanding of the strategic nature of the market participants. Unfortunately, however, this type of work would require microscopic data on informed traders and market makers. We leave it for future research when such data eventually become available.

\section{References}

Admati, A. R. and Pfleiderer, P., 'A theory of intraday patterns: volume and price variability', Review of Financial Studies, Vol. 1 no. 1, Spring, 1988, pp. 3-40.

Bagnoli, M., Kross, W. and Watts, S. G., 'The information in management's expected earnings report date: a day late, a penny short', Journal of Accounting Research, Vol. 40 no. 5, December, 2002, pp. 1275-96.

Ball, R. and Brown, P., 'An empirical evaluation of accounting income numbers', Journal of Accounting Research, Vol. 6 no. 2, 1968, pp. 159-78.

Ball, R. and Kothari, S. P., 'Security returns around earnings announcements', Accounting Review, Vol. 66 no. 4, October, 1991, pp. 718-38.

Bamber, L. S., 'Unexpected earnings, firm size, and trading volume around quarterly earnings announcements', Accounting Review, Vol. 62 no. 3, 1987, pp. 510-32.

Bernard, V. L. and Thomas, J. K., 'Post-earnings-announcement drift: delayed price response or risk premium?', Journal of Accounting Research, Vol. 27, 1989, pp. 1-36.

Betzer, A. and Theissen, E., 'Insider trading and corporate governance: the case of Germany', European Financial Management, Vol. 15 no. 2, 2009, pp. 402-29.

Brandt, M., Kishore, R., Santa-Clara, P. and Venkatachalam, M., 'Earnings announcements are full of surprises', Duke University Working Paper, 2008.

Bris, A., 'Do insider trading laws work?', European Financial Management, Vol. 11 no. 3, 2005, pp. 267-312.

Chae, J., 'Trading volume, information asymmetry, and timing information', Journal of Finance, Vol. 60 no. 1, 2005, pp. 413-42.

Chordia, T., Roll, R. and Subrahmanyam, A., 'Market liquidity and trading activity', Journal of Finance, Vol. 56 no. 2, April, 2001, pp. 501-30.

Cohen, L., Malloy, C. and Pomorski, L., 'Decoding insider information', Harvard Business School Working Paper, 2009.

Cornell, B. and Sirri, E. R., 'The reaction of investors and stock prices to insider trading', Journal of Finance, Vol. 47 no. 3, July, 1992, pp. 1031-59. 
Eyssell, T. H. and Arshadi, N., 'Insiders, outsiders, or trend chasers? An investigation of pre-takeover transactions in the shares of target firms', Journal of Financial Research, Vol. 16 no. 1, Spring, 1993, pp. 49-59.

Foster, F. D. and Viswanathan, S., 'Strategic trading with asymmetrically informed traders and longlived information', Journal of Financial and Quantitative Analysis, Vol. 29 no. 4, December, 1994, pp. 499-518.

Foster, F. D. and Viswanathan, S., 'Strategic trading when agents forecast the forecasts of others', Journal of Finance, Vol. 51 no. 4, September, 1996, pp. 1437-78.

Friederich, S., Gregory, A., Matatko, J. and Tonks, I., 'Short-run returns around the trades of corporate insiders on the London Stock Exchange', European Financial Management, Vol. 8 no. 1, 2002, pp. 7-30.

Garfinkel, J. A., 'New evidence on the effects of federal regulations on insider trading: the Insider Trading and Securities Fraud Enforcement Act (ITSFEA)', Journal of Corporate Finance, Vol. 3 no. 2, April, 1997, pp. 89-111.

Holden, C. W. and Subrahmanyam, A., 'Long-lived private information and imperfect competition', Journal of Finance, Vol. 47 no. 1, March, 1992, pp. 247-70.

Huddart, S., Hughes, J. S. and Levine, C. B., 'Public disclosure and dissimulation of insider trades', Econometrica, Vol. 69 no. 3, May, 2001, pp. 665-81.

Huddart, S., Ke, B. and Shi, C., 'Jeopardy, non-public information, and insider trading around SEC 10-K and 10-Q filings', Journal of Accounting and Economics, Vol. 43 no. 1, March, 2007, pp. 3-36.

Jagolinzer, A. and Roulstone, D., 'Litigation risk and the timing of insiders' trades', Working Paper (Stanford University, 2007).

Jagolinzer, A. and Roulstone, D., 'The effects of insider trading regulation on trade timing, litigation risk and profitability’, Working Paper (Stanford University, 2009).

Jarrell, G. A. and Poulsen, A. B., 'Stock trading before the announcement of tender offers: insider trading or market anticipation?', Journal of Law, Economics, and Organization, Vol. 5 no. 2, Fall, 1989, pp. 225-48.

Jeng, L. A., Metrick, A. and Zeckhauser, R., 'Estimating the returns to insider trading: a performance-evaluation perspective', Review of Economics and Statistics, Vol. 85 no. 2, May, 2003, pp. 453-71.

Jensen, M. C. and Ruback, R. S., 'The market for corporate control: the scientific evidence', Journal of Financial Economics, Vol. 11 no. 1-4, 1983, pp. 5-50.

Ke, B., Huddart, S. and Petroni, K. R., 'What insiders know about future earnings and how they use it: evidence from insider trades', Journal of Accounting and Economics, Vol. 35 no. 3, August, 2003, pp. 315-46.

Keown, A. J. and Pinkerton, J. M., 'Merger announcements and insider trading activity: an empirical investigation', Journal of Finance, Vol. 36 no. 4, September, 1981, pp. 855-69.

Kyle, A. S., 'Continuous auctions and insider trading', Econometrica, Vol. 53 no. 6, November, 1985, pp. 1315-35.

Kyle, A. S., 'Informed speculation with imperfect competition', Review of Economic Studies, Vol. 56 no. 3, July, 1989, pp. 317-55.

Lakonishok, J. and Lee, I., ‘Are insider trades informative?' Review of Financial Studies, Vol. 14 no. 1, Spring, 2001, pp. 79-111.

Lee, I., Lemmon, M., Li, Y. and Sequeira, J., 'The effects of regulation on the volume, timing and profitability of insider trading', Working Paper (National University of Singapore, 2008).

Lei, Q., Rajan, M. and Wang, X., 'Profiting from trading insights of exceptional insiders', Working Paper (Southern Methodist University, 2010).

Meulbroek, L. K., 'An empirical analysis of illegal insider trading', Journal of Finance, Vol. 47 no. 5, December, 1992, pp. 1661-99.

Milgrom, P. and Stokey, N., 'Information, trade and common knowledge', Journal of Economic Theory, Vol. 26 no. 1, February, 1982, pp. 17-27.

Mitchell, M., Pulvino, T. and Stafford, E., 'Price pressure around mergers', Journal of Finance, Vol. 59 no. 1, February, 2004, pp. 31-63. 
Roulstone, D., 'Insider trading and the information content of earnings announcements', Working Paper (University of Chicago, 2006).

Rozeff, M. S. and Zaman, M. A., 'Overreaction and insider trading: evidence from growth and value portfolios', Journal of Finance, Vol. 53 no. 2, April, 1998, pp. 701-16.

Seyhun, H. N., 'Insiders' profits, costs of trading, and market efficiency', Journal of Financial Economics, Vol. 16 no. 2, 1986, pp. 189-212.

Seyhun, H. N., 'The information content of aggregate insider trading', Journal of Business, Vol. 61 no. 1, January, 1988, pp. 1-24.

Seyhun, H. N., Investment Intelligence from Insider Trading (MIT Press, 1998).

Sivakumar, K. and Waymire, G., 'Insider trading following material news events: evidence from earnings', Financial Management, Vol. 23 no. 1, 1994, pp. 23-32.

Wang, J., 'A model of competitive stock trading volume', Journal of Political Economy, Vol. 102 no. 1, February, 1994, pp. 127-68.

Wang, M.-C. and Zu, L.-P., 'Trade timing, price volatility and serial correlation', European Financial Management, Vol. 19(5), 2013, pp. 911-34. 